\title{
Thermal Activation of Electrochemical Seed Surfaces for Selective and Tunable Hydrophobic Patterning
}

Alistair Speidel, James W. Murray, Ivan Bisterov, Jonathon Mitchell-Smith, Christopher Parmenter, and Adam T. Clare*

Cite This: ACS Appl. Mater. Interfaces 2020, 12, 7744-7759

Read Online

\section{ACCESS | Lill Metrics \& More | 回 Article Recommendations ｜（） Supporting Information}

ABSTRACT: Remarkable interfacial behaviors are observed in nature. Our efforts, directed toward replicating the structures, chemistries, and therefore functional properties of natural nonwetting surfaces, are competing with the result of billions of years of natural selection. The application of man-made surfaces is challenged by their poor longevity in aggressive environmental or applied service conditions. This study reports on a new approach for the creation of multiscale hierarchical surface patterns in metals, which exploits thermodynamic phenomena in advanced manufacturing processes. While hydrophobic coatings can be produced with relative ease by electrodeposition, these fractal-type structures tend to have poor structural integrity and hence are not durable. In this method, "seed surfaces" are directly written onto substrates by

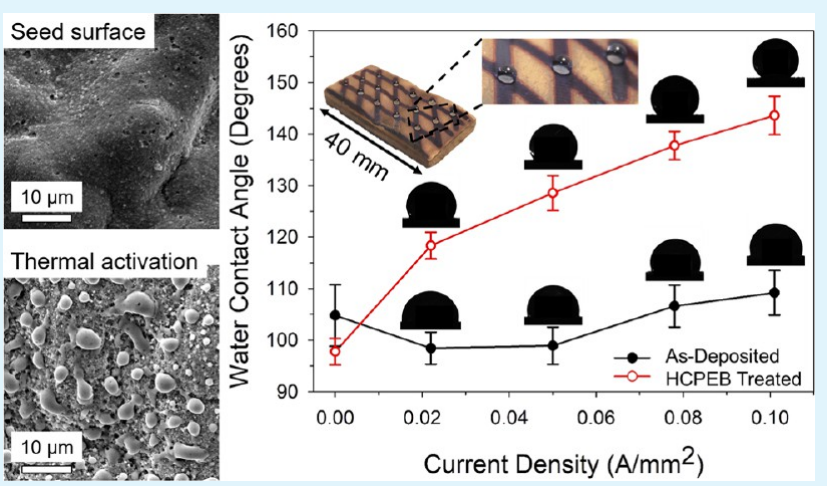
selective electrodeposition, after which they are irradiated by a large-area, pulsed electron beam to invoke a beading phenomenon, which is studied here. The length scale of these beads is shown to depend upon the melt time of the liquid metal. The created surfaces are shown to yield high water contact angles $\left(145^{\circ}\right)$ without subsequent chemical modification, and high adhesion properties reminiscent of the "rose petal" hydrophobic effect. The size and morphology and hence the hydrophobic effect of the surface beads generated are correlated with the thickness of the electrodeposited coating and hence the melt lifetime upon electron irradiation. This new rapid approach for tunable hydrophobic surface creation has applications for developing precision hydrophobic patterns and is insensitive to surface complexity.

KEYWORDS: backscattered electron, electrochemical jet processing, focus variation microscopy, high-current pulsed electron beam, interelectrode gap, water contact angles

\section{INTRODUCTION}

Manipulation of fluid-facing properties of a material can radically alter the interaction between its surface and surroundings. There are profound benefits where wettability can be controlled, both in terms of wetting regime and magnitude, in a location-specific manner across a given surface for a range of engineering applications. These include microfluidics ${ }^{1}$ as well as self-cleaning ${ }^{2}$ and corrosion-resistant surfaces. ${ }^{3,4}$ Hydrophobic $\mathrm{Cu}$ surfaces have also been shown to significantly increase the efficiency of $\mathrm{CO}_{2}$ reduction into usable fuel chemistries. ${ }^{5}$ This has wide-reaching implications for increasing selectivity in other heterogeneous catalytic systems. Technology that creates durable interfaces of this kind is yet to be demonstrated.

Surface wettability is governed by both chemistry and topography. The interaction between these varies greatly across material systems. Fundamentally, the wettability of a flat surface depends on the thermodynamic equilibrium of the free energy at the solid-liquid-vapor interface, which is described by the Young equation. ${ }^{6}$ Low-surface-energy materials, which display poor solid-liquid adhesion, tend toward poor wettability. Metals, which have high surface energy, tend toward high wettability by homogeneous wetting without additional surface modification. ${ }^{6}$ Surface topography also influences the apparent liquid contact angle, which is generally described by the Wenzel and Cassie-Baxter models. Both dictate that rougher surfaces exaggerate pre-existing hydrophobicity or hydrophilicity. ${ }^{7,}$

The traditional approach to hydrophobic surface generation involves deposition or top-down processing ${ }^{9}$ of materials with intrinsic hydrophobicity (considering surface free energy), such as some polymers and their composites. ${ }^{10}$ These are often not hard-wearing ${ }^{11}$ and can be susceptible to photodegradation, limiting their environmental longevity. To increase

Received: November 6, 2019

Accepted: January 24, 2020

Published: January 24, 2020 


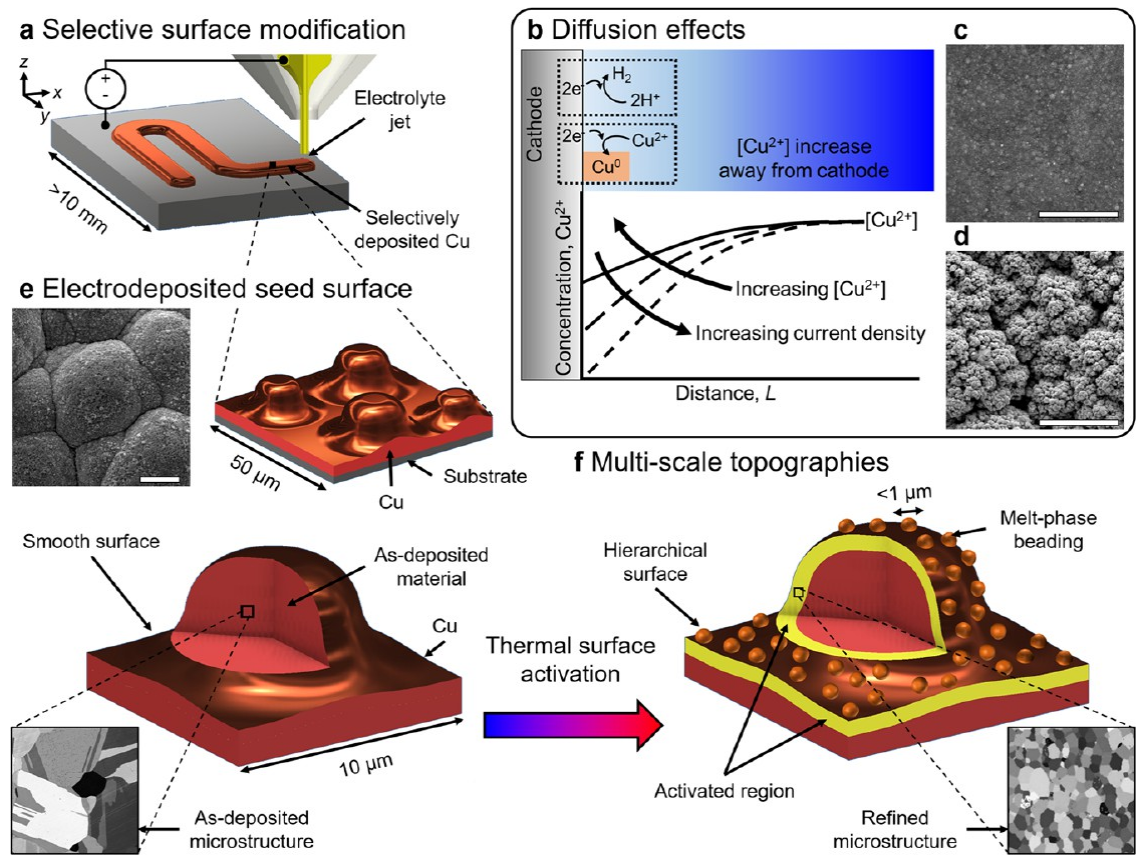

Figure 1. Combined approach for the creation of functional surfaces. (a) Schematic of a 3-axis electrochemical jet processing (EJP) apparatus used in this study used to generate selective coatings. An electrolyte jet is supplied from the nozzle onto the substrate, and current is applied. (b) Topography is dictated by the supply of $\mathrm{Cu}^{2+}$ to the surface, which reduces as the current density is increased (solid lines to dashed lines indicate this change). (c) Where the rate of cation supply is faster than the reaction (low current density or high bulk concentration), continuous deposits are generated. (d) Where the surface concentration is exhausted (high current density or low bulk concentration), diffusion-limited structures are formed with poor mechanical properties and hydrogen embrittlement. (e) Surfaces with greater continuity can instead be activated thermally (f) to enhance both morphology and micro/nanostructure. Scanning electron microscopy (SEM) scale bars are $10 \mu \mathrm{m}$.

applicability, more robust materials are required, such as metals, $^{12}$ ceramics, ${ }^{13}$ and their composites. ${ }^{14}$ In contrast, metals generally display good mechanical properties such as hardness, wear resistance, and specific strength, in addition to high-temperature stability as well as good thermal and electronic conductivity.

High apparent water contact angles (WCAs) on highsurface-area metals, such as those created by electrodeposition, have been attributed to the time-dependent adsorption of adventitious hydrocarbon species, ${ }^{15}$ or $\mathrm{O}_{2}$ (for example, on $\mathrm{CuO}$ surface oxides ${ }^{16}$ ), under ambient conditions. This is useful for real-world applications where environmental conditions cannot be controlled. However, typically, electrodeposition is used to create high-performance surfaces with low surface roughness. Through overcurrent provision and locally exhausting metal cation concentration (see Figure $1 \mathrm{~b}$ ), it is possible to create structures at scales affecting wettability (see Figure 1d). Coatings of this kind often have poor substrate bonding based on a powdery and/or dendritic morphology, wherein electrodeposition transitions from a continuous film deposition to discrete nucleation and growth. ${ }^{17}$ Deposition is promoted on pre-existing asperities that shield recesses and depressions, leading to discontinuous surfaces with self-similar hierarchical morphologies. ${ }^{18,19}$ Despite exhibiting favorable hydrophobic properties, ${ }^{20}$ these structures suffer from inferior mechanical properties compared to bulk materials and hydrogen embrittlement.

To make a meaningful impact upon daily life, the next generation of hydrophobic coatings will be rapidly/flexibly manufactured, tunable, and robust. A solution is therefore required to manipulate and enhance surface functionality of such morphologies while retaining or enhancing structural and interfacial integrity of electrodeposited coatings. Here, $\mathrm{Cu}$ is used as a model material system to demonstrate that electrochemically seeded surfaces can result in robust functional coatings. In this study, $\mathrm{Cu}$ films were selectively electrodeposited using electrochemical jet processing (EJP), under ambient conditions. ${ }^{21}$ Relatively high electrolyte impingement velocities (up to $30 \mathrm{~m} / \mathrm{s}$ ) suppress the diffusion layer and increase the surface cation supply rate. This enables a greater limiting current condition in comparison to conventional bath deposition. ${ }^{22}$ An operational schematic is shown in Figure 1. EJP is achieved using multiple axes, enabling complex geometry surface processing. ${ }^{23}$

It was theorized here that appropriate thermal activation and recrystallization of the as-deposited coating could allow enhancement of functionality and integrity. It was proposed that this could be achieved through melting and coalescence of the liquid metal, where the control of cooling rates dictates morphology length scales (see Figure 1e,f). To achieve this, an energy source localized to the coating, exhibiting high cooling rates and deliverable in an inert atmosphere, was required. In this study, irradiation of electrodeposited "seed" surfaces was undertaken using a high-current pulsed electron beam (HCPEB). In prior work, the process has been shown to be capable of significantly modifying the coating morphology and creating dense near-surface regions containing nanostructured grains. ${ }^{24}$ Specific energy densities (up to $0.2 \mathrm{~J} / \mathrm{mm}^{225}$ ) and appropriate pulse durations $\left(2-4 \mu \mathrm{s}^{25}\right)$ allow energy to be transferred in a thin surface layer $(<10 \mu \mathrm{m})$, generating high temperatures beyond the melting or even boiling points of most metals. Small electron penetration depths $(<3 \mu \mathrm{m}$ for dense $\left.\mathrm{Cu}^{26,27}\right)$ at conventionally applied acceleration voltages $(10-40 \mathrm{kV})$ in HCPEB indicate that the energy of each pulse 
is discharged into microscopic surface volumes. This means electron-material interactions during HCPEB are characterized by extremely high surface heating and cooling rates (up to $10^{9} \mathrm{~K} / \mathrm{s}$ ), which favor nanoscale grain formation, and nonequilibrium phase creation. ${ }^{28}$ Topography enhancements are assisted by the high surface tension of molten metals $(\mathrm{Cu} \approx$ $1.30 \mathrm{~N} / \mathrm{m}$ at $1083^{\circ} \mathrm{C}^{29}$ ), which enables "micro/nanobeading". Alongside EJP, HCPEB has been shown to be robust to nonplanar surface geometries, and in this study, the two techniques have been applied together to create and sculpt hierarchical surfaces on complex-shaped parts.

In the present work, tunable, directly written hydrophobic metal coatings are demonstrated. Manipulation of EJP is used to yield a variety of seed structures, which are consequently subject to activation by HCPEB, although the process could be extended to other dynamic heat sources, such as relatively common scanning laser systems, using existing equipment to process materials at a low cost and intervention level. The hydrophobicity of these surfaces before and after HCPEB is assessed through sessile droplet analysis and dynamic contact angle analysis, and stability and durability trials are conducted. Detailed surface and cross-sectional microscopy are performed to determine the underlying structure of modified coatings, as well as propose a new mechanism by which enhancement of hydrophobic morphologies on $\mathrm{Cu}$ coatings is achieved. While the present study deals only with $\mathrm{Cu}$, relatively high liquid surface tension (as strongly cohesive liquids) and high thermal conductivity are broad properties of metallic materials (see Supporting Information Table S1). It is therefore likely that an extended study would reveal that by exploiting the adapted parameters, the same phenomena could be replicated in alternate materials and their alloys, where it is possible to create them.

\section{EXPERIMENTAL SECTION}

2.1. Materials. Stainless steel (SUS304) was used as a substrate material for all experiments. Samples were cut from a grit-blasted $\left(\mathrm{Al}_{2} \mathrm{O}_{3}, 212 \mu \mathrm{m}\right.$ grit size, D50) flat bar and washed sequentially with deionized water and acetone prior to processing. Electroplating was performed using a copper sulfate electrolyte $(1 \pm 0.01 \mathrm{M})$ made from the as-received salt $\left(\mathrm{CuSO}_{4} \cdot 5 \mathrm{H}_{2} \mathrm{O}\right.$, Acros) and deionized water without prior preparation or additives. Electrolyte acidity $(\mathrm{pH} 2.8 \pm$ $0.1)$ and the electrolytic conductivity, $\kappa_{\mathrm{e}}(46.84 \pm 0.04 \mathrm{mS} / \mathrm{cm}$ at 21.4 ${ }^{\circ} \mathrm{C}$ ), were measured prior to experimentation. Electrolyte density was measured volumetrically $\left(1.16 \pm 0.1 \mathrm{~g} / \mathrm{mL}\right.$ at $\left.20.1{ }^{\circ} \mathrm{C}\right)$.

2.2. Methods and Theory. Electrochemical jet processing (EJP) was undertaken using a 3 -axis computer numerical control (CNC) apparatus. ${ }^{30}$ A direct current power supply was used in a currentlimited configuration, with the electrode potential allowed to float dependent on the interelectrode gap (IEG) resistance. The electrolyte was recirculated during processing. For all experiments, plating was undertaken using a $1 \mathrm{~mm}$ internal diameter, $d$, a nozzle at a constant jet impingement velocity, $\nu_{\mathrm{j}}(16.3 \pm 0.15 \mathrm{~m} / \mathrm{s})$, IEG, $H(0.5 \mathrm{~mm})$, translation velocity, $\nu_{\mathrm{f}}(2 \mathrm{~mm} / \mathrm{s})$, and striation separation $(0.5 \mathrm{~mm})$. The effect of varying deposit thickness was appraised over a $10 \times 10$ $\mathrm{mm}$ total patch area, $A_{\mathrm{p}}$, by superimposing CNC toolpaths over decreasing areas. This was undertaken at a constant supply current density, $J_{n}\left(0.022 \mathrm{~A} / \mathrm{mm}^{2}\right)$, where $J_{n}$ is the ratio between the applied current, $I$, and planar nozzle area, $A_{n}$. This is a simplified description of the actual current density distribution that is Gaussian under standard operational conditions. ${ }^{31}$ The cumulative charge transferred, $Q_{T}$, was controlled for each area, where the areal charge density is the ratio between $Q_{T}$ and $A_{\mathrm{p}}$. Nonuniversal parameters for preliminary experimentation are outlined in Table 1 .

Deposited foil mass, $M$, may be approximated with the knowledge of current efficiency, $\eta$, by applying Faraday's law; see eq 1
Table 1. EJP Parameters for Deposit Thickness Experiments

$\begin{array}{ccccc}\begin{array}{c}\text { patch } \\ \text { number }\end{array} & \begin{array}{c}\text { patch } \\ \text { dimensions } \\ (\mathrm{mm})\end{array} & \begin{array}{c}\text { layers/ } \\ \text { patch }(n)\end{array} & \begin{array}{c}\text { cumulative } \\ \text { layers }(n)\end{array} & \begin{array}{c}\text { areal charge } \\ \text { density }\left(\mathrm{C} / \mathrm{mm}^{2}\right)\end{array} \\ 1 & 10 \times 10 & 2 & 2 & 0.04 \pm 0.02 \\ 2 & 10 \times 8 & 3 & 5 & 0.10 \pm 0.02 \\ 3 & 10 \times 6 & 5 & 10 & 0.20 \pm 0.02 \\ 4 & 10 \times 4 & 5 & 15 & 0.30 \pm 0.02 \\ 5 & 10 \times 2 & 5 & 20 & 0.40 \pm 0.02 \\ M & \\ M & & & & \end{array}$

where $F$ is the Faraday constant, $m_{\mathrm{A}}$ is the molar mass of $\mathrm{Cu}$, and $z$ is the charge number of the reaction. Considering $\mathrm{Cu}$ density $(8.96 \mathrm{mg} /$ $\mathrm{mm}^{3}$ at $25{ }^{\circ} \mathrm{C}$ ) will enable approximations of deposit volume and thickness. $\eta$ tends toward 1 at low current densities or high $\mathrm{Cu}^{2+}$ concentrations, ultimately, where $\mathrm{Cu}^{2+}$ reduction is the dominant charge-transfer reaction. In EJP, the $\mathrm{Cu}^{2+}$ surface concentration becomes zero as the limiting current is exceeded, and alternate chargetransfer reactions dominate, e.g., water reduction and evolving hydrogen (see Figure 1b). Chin and $\mathrm{Hsueh}^{32,33}$ derived limiting current densities for an unsubmerged impinging jet; see eq 2

$$
J_{\lim }=0.9 \frac{F z C_{B} D}{d} S c^{1 / 3} R^{1 / 2}\left(\frac{H}{d}\right)^{-0.09}
$$

where $C_{\mathrm{B}}$ is the bulk $\mathrm{Cu}^{2+}$ concentration, $D$ is the $\mathrm{Cu}^{2+}$ diffusivity, $\mathrm{Sc}$ is the Schmidt number (ratio between the kinematic viscosity, $\nu$, and diffusivity), and $R e$ is the Reynolds number of the electrolyte jet

$$
R e=\frac{\nu_{j} d}{\nu}
$$

For EJP conditions outlined above, $J_{\lim }$ is expected to be $\approx 0.185 \mathrm{~A} /$ $\mathrm{mm}^{2}$, significantly greater than low flow bath electrodeposition. Hierarchical surfaces were created by depositing coatings $(10 \times 10$ $\mathrm{mm}$ ) at different supply current densities. Parameters for these experiments are outlined in Table 2 , returning approximate deposition

Table 2. EJP Parameters Used To Characterize Topography-Beam Interactions

\begin{tabular}{ccccc}
$\begin{array}{c}\text { current density, } \\
J_{n}\left(\mathrm{~A} / \mathrm{mm}^{2}\right)\end{array}$ & $\begin{array}{c}\text { applied } \\
\text { current, } I(\mathrm{~A})\end{array}$ & $\begin{array}{c}\text { layers } \\
(n)\end{array}$ & $\begin{array}{c}\text { areal charge } \\
\text { density }(\mathrm{C} / \\
\left.\mathrm{mm}^{2}\right)\end{array}$ & $\begin{array}{c}\text { surface }\left[\mathrm{Cu}^{2+}\right] \\
\text { concentration } \\
(\mathrm{M})\end{array}$ \\
$0.022 \pm 0.011$ & $0.020 \pm 0.01$ & 19 & $0.38 \pm 0.19$ & $0.88 \pm 0.05$ \\
$0.050 \pm 0.011$ & $0.045 \pm 0.01$ & 8 & $0.36 \pm 0.08$ & $0.73 \pm 0.05$ \\
$0.078 \pm 0.011$ & $0.070 \pm 0.01$ & 5 & $0.35 \pm 0.05$ & $0.58 \pm 0.05$ \\
$0.101 \pm 0.011$ & $0.090 \pm 0.01$ & 4 & $0.36 \pm 0.04$ & $0.45 \pm 0.05$ \\
\hline
\end{tabular}

masses of $11.8-12.8 \mathrm{mg}$ for these areal plating operations (where $\eta=$ 1). The applied current densities were limited to $0.101 \mathrm{~A} / \mathrm{mm}^{2}$, below the predicted limiting current condition for this EJP setup. Knowledge of the limiting current density allows the approximation of the effective $\mathrm{Cu}^{2+}$ surface concentration, $C$, at a given current density, according to eq 4

$$
C=C_{\mathrm{B}} \frac{J_{\lim }-J}{J_{\lim }}
$$

Anisotropic wetting patterns were created by electrochemical etching using the same EJP setup. In this experiment, the workpiece polarity was reversed to be the anode, while a $0.25 \mathrm{~mm}$ nozzle was applied to remove the material using the $\mathrm{NaCl}(2 \mathrm{M})$ electrolyte, with a striation separation of $1.00 \mathrm{~mm} . \nu_{\mathrm{j}}, \nu_{\mathrm{f}}$, and $H$ were maintained at $16.3 \mathrm{~m} / \mathrm{s}, 2.00$ $\mathrm{mm} / \mathrm{s}$, and $0.50 \mathrm{~mm}$, respectively. Current was supplied at $0.100 \pm$ $0.01 \mathrm{~A}$, resulting in an approximate current density of $2.00 \pm 0.021 \mathrm{~A} /$ $\mathrm{mm}^{2}$ using the smaller diameter nozzle. 


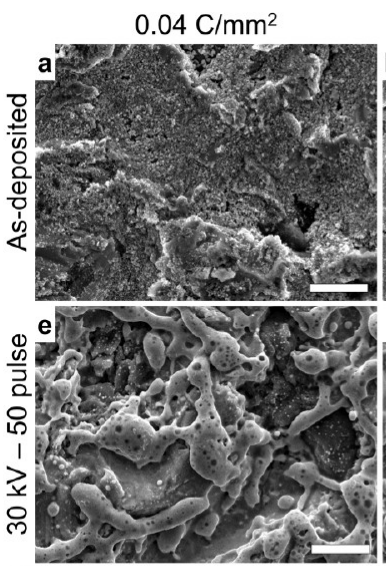

i Cu thickness and bead size

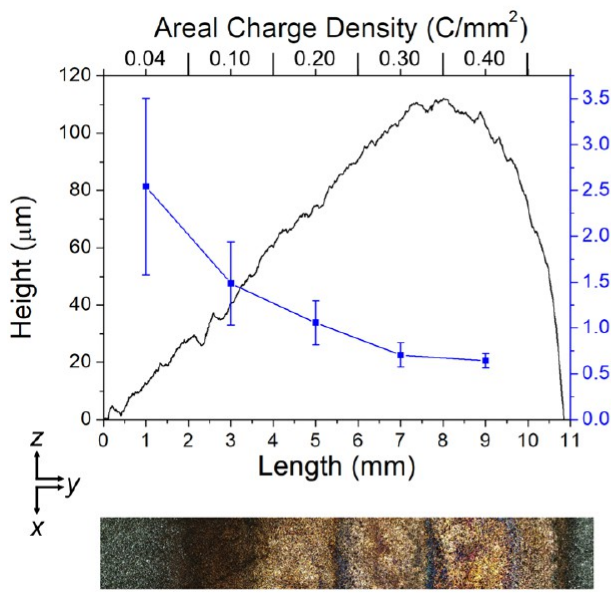

$0.10 \mathrm{C} / \mathrm{mm}^{2}$

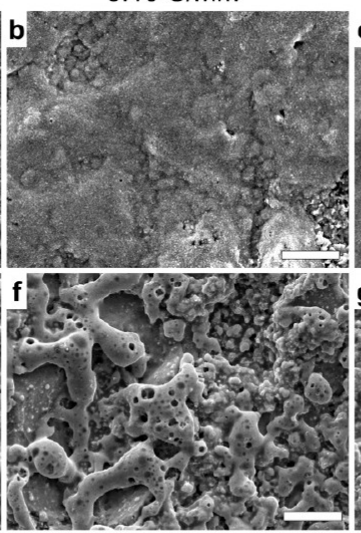

$0.20 \mathrm{C} / \mathrm{mm}^{2}$

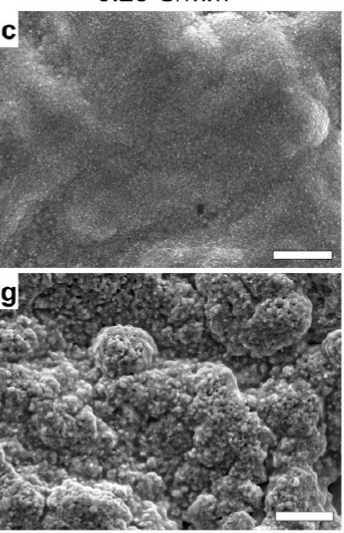

$0.40 \mathrm{C} / \mathrm{mm}^{2}$

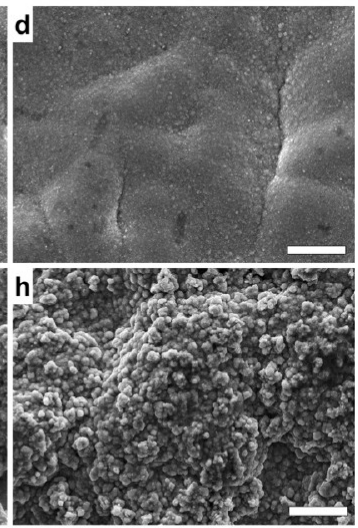

k Thick-film Cu

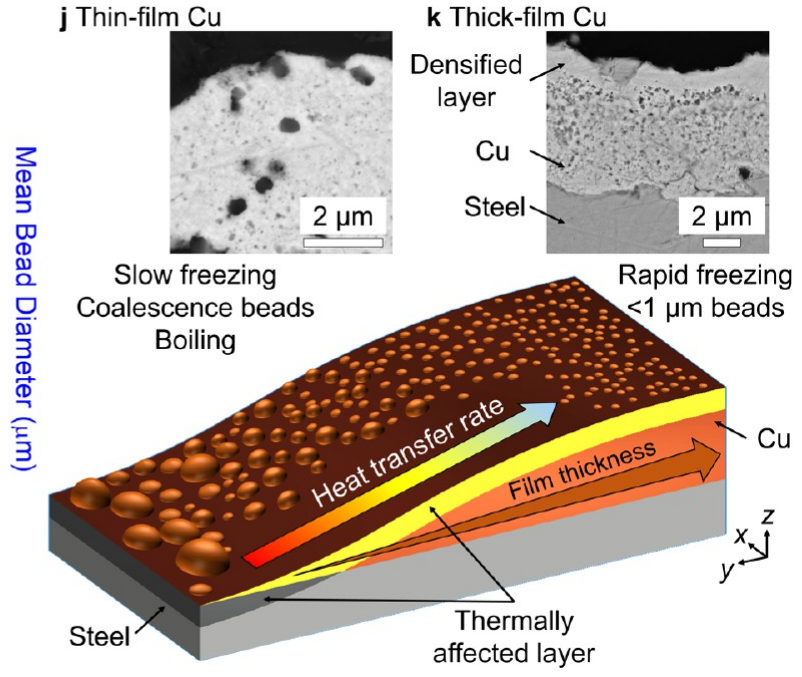

Figure 2. $\mathrm{Cu}$ layer thickness influences the resulting surface topography after HCPEB ( $30 \mathrm{kV}, 50 \mathrm{cycles})$. SE micrographs of surfaces of the asdeposited $\mathrm{Cu}$ films $\left(J_{n}=0.022 \mathrm{~A} / \mathrm{mm}^{2}\right)$ before $(\mathrm{a}-\mathrm{d})$ and after $(\mathrm{e}-\mathrm{h})$ HCPEB. Topography develops features conducive to hydrophobicity after the electron beam processing. (i) Mean thickness (FVM, 20× objective), with the accompanying optical micrograph of the as-deposited surface $(11.0 \times 1.51 \mathrm{~mm})$. (j) For thin-film $\mathrm{Cu}$ deposits, heat transfer is poor across the $\mathrm{Cu}-\mathrm{Cr}$ oxide-substrate interface and molten balls coalesce, where heat localization enables evaporation and pore formation, shown in the section view BSE micrograph inset. (k) Thicker films effectively transfer heat from the near-surface, and molten beads freeze before full coalescence. Fusion of microballs through sintering and melting mechanisms densifies the top layer, shown in the section view BSE micrograph inset. SEM scale bars are $10 \mu \mathrm{m}$ unless indicated.

After EJP, the samples were cleaned with deionized water and dried under ambient conditions prior to HCPEB processing (Sodick PF32A EBM). An acceleration voltage of $30 \mathrm{kV}\left(\approx 0.12 \mathrm{~J} / \mathrm{mm}^{2}\right.$ energy density) was applied for 50 discrete discharge cycles. This electron beam voltage was selected to ensure material modification through the coating thickness, where this was desired. A $30 \mathrm{kV}$ electron beam will lead to an electron penetration depth $\approx 2.8 \mu \mathrm{m}$ in a homogeneous $\mathrm{Cu}$, which typically results in microstructural changes up to $10-20$ $\mu \mathrm{m}$ into the material, when processing dense samples. ${ }^{24}$ Fifty discharge cycles were chosen in an effort to ensure the material and topographic effects were homogenized across the sample surface.

Discontinuous and porous (lower density) films expected when deposition approaches the limiting current condition will result in deeper electron-affected zones. Argon pressure $(0.05 \mathrm{~Pa})$ and pulse duration $(\approx 2 \mu \mathrm{s})$ were unchanged throughout experimentation. Strong surface tensile effects explain disadvantageous balling phenomena in powder bed additive manufacturing, which inhibits subsequent layer deposition. ${ }^{34,35}$ For liquids, the ratio between gravitational and surface tensile forces can be expressed through the dimensionless Bond number; ${ }^{36}$ see eq 5

$$
B o=\frac{\Delta \rho g L^{2}}{\gamma}
$$

while the ratio of capillary and viscous forces can be expressed by the dimensionless Laplace number

$$
L a=\frac{\gamma \rho L}{\nu^{2}}
$$

where $\Delta \rho$ is the density difference between the liquid and gas phases, $g$ is acceleration due to gravity, $L$ is the characteristic length, and $\gamma$ is the liquid surface tension. Vacuum chamber gas (Ar) density can be calculated by the ideal gas law. $\rho \operatorname{Ar}_{(\mathrm{g})}\left(\approx 7.93 \times 10^{-4} \mathrm{mg} / \mathrm{mm}^{3}\right)$ at chamber pressure is negligible compared with $\rho \mathrm{Cu}_{(1)}$ at the melting point: $1083{ }^{\circ} \mathrm{C}\left(7.99 \mathrm{mg} / \mathrm{mm}^{3}\right)$, so $\Delta \rho$ is taken as the latter. $L$ here is taken as the approximate melted depth in $\mathrm{HCPEB}(\approx 2-10 \mu \mathrm{m})$. For these conditions, the Bond number is $\approx 10^{-5}$, and $\mathrm{La} \approx 10^{4}$, demonstrating that surface tensile effects dominate gravitational and viscous forces across the length scales and conditions in HCPEB. This indicates that parameter selection with the intention of modulating the $\mathrm{Cu}$ melt lifetime can enable the formation and control of surfacetension-induced topographies at small length scales.

2.3. Characterization. Electrolytic conductivity was measured with a Mettler-Toledo S3 conductivity meter. After generation, the surfaces were appraised using an optical focus variation microscopy (FVM) (Alicona G5, 2.5 $\times, 20 \times, 50 \times$ objectives), as well as backscattered electron (BSE) and secondary electron (SE) microscopy (Philips XL-30 and JEOL 7100F SEM). Cross-sectional scanning transmission electron microscopy (STEM) imaging and 

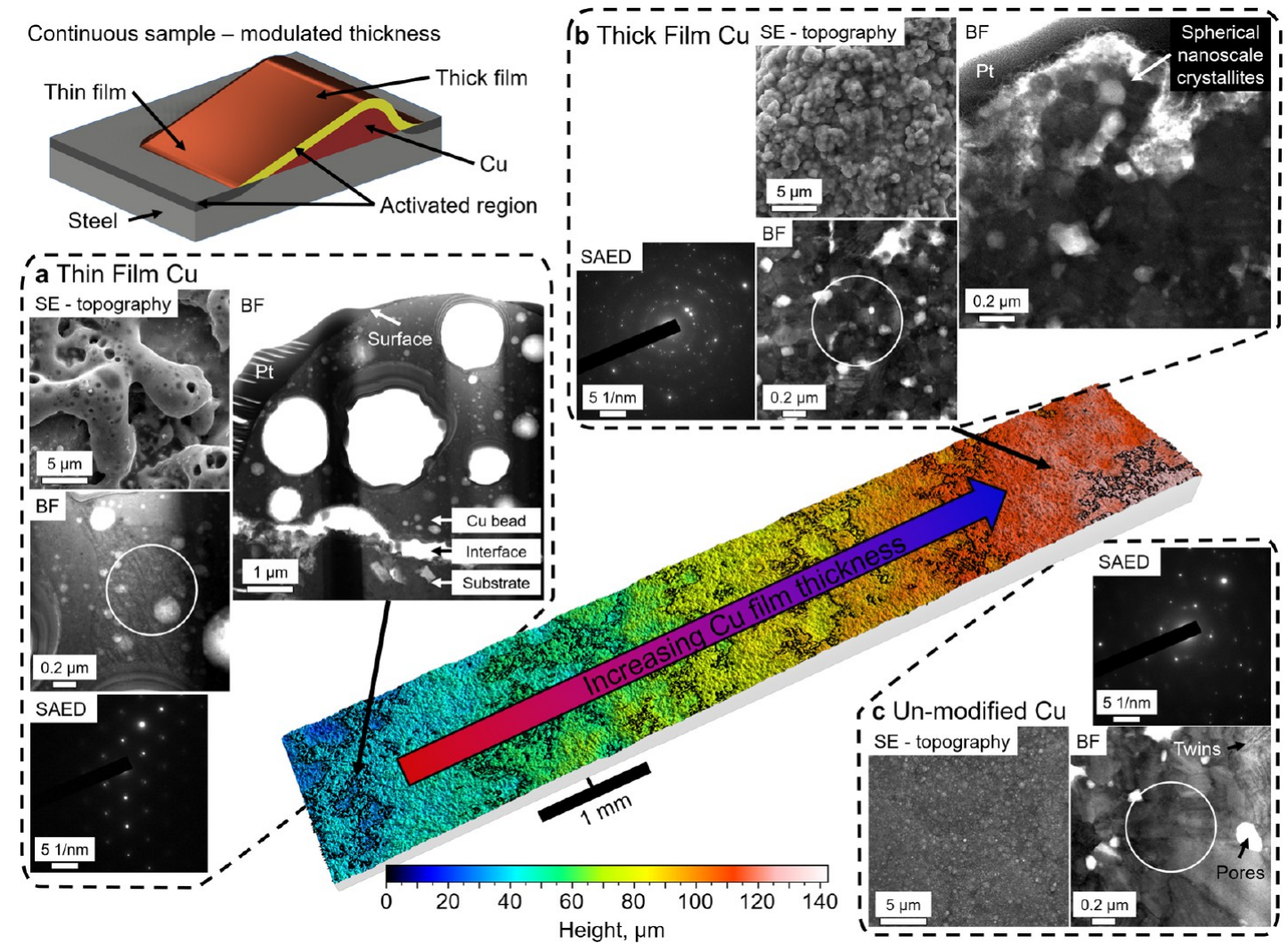

Figure 3. Metallurgies across length scales in a single sample. Deposit thickness dictates the cooling rate of liquid $\mathrm{Cu}$. This is evidenced by the range of metallurgies visible in the same sample wherein deposit thickness is modulated. (a) In the thin-film region, surface topography is dominated by relatively large beads $(2-20 \mu \mathrm{m})$, indicating coalescence of molten $\mathrm{Cu}$. This is shown in the BF micrograph and the single-crystal SAED pattern over the sampling area. This grain size is striking in comparison to the microstructure of the thick-film region. (b) Thick-film region shows submicron topographies upon irradiation. Nanocrystalline grains are observed in the BF micrograph, supported by the multiple grains evident in the SAED pattern, indicative of higher cooling rates. For comparison, the unmodified material has an apparent grain size between the two modified regions, while the SAED pattern is more consistent with a single crystal in the sampling area. White rings demarcate approximate SAED pattern acquisition areas. Height contour spacing (black lines) is $20 \mu \mathrm{m}$.

selected area electron diffraction (SAED) patterns were acquired using a JEOL 2100+ transmission electron microscope, on samples prepared by a focused ion beam (FIB) milling (FEI Quanta 200 3D). Energy-dispersive X-ray spectroscopy (EDS) was carried out using Oxford Instruments Xmax 80 detectors (acceleration voltage: XL-30 SEM $20 \mathrm{kV}, 2100+$ TEM $100 \mathrm{kV}$ ). EDS spectra were acquired after 1 min of data collection, and EDS maps were acquired after $>5$ min of data collection. X-ray diffraction (XRD) was performed using a Bruker D8 Da Vinci diffractometer with $\mathrm{Cu} \kappa \alpha$ radiation. Samples were left for $>1$ month prior to the microstructural study to account for self-annealing phenomena, which are prevalent in the electrodeposited $\mathrm{Cu}^{37} S_{\mathrm{q}}$ surface roughness and $S_{\mathrm{z}}$ maximum height were characterized by FVM surface datasets after leveling (least-squares method) and waviness filtering ( $25 \mu \mathrm{m}$ cutoff) using the MountainsMap software. $\mathrm{Cu}$ surface beads were sized from SE micrographs using the Canny edge detection routine $(3 \times 3$ Gaussian filter $)$ using ImageJ (see Supporting Information Figure S1).

Sessile water contact angle (WCA) was measured (Krüss DSA100) on processed surfaces equilibrated for $>1$ week at atmospheric conditions with deionized water $(3 \pm 0.2 \mu \mathrm{L}$ droplet volume $)$ and the same surfaces after 30 weeks under atmospheric conditions. Droplets were left for $>3$ min until an apparent steady state was observed. Five repeats were acquired for each parameter. Advancing, $\theta_{a}$, and receding, $\theta_{\mathrm{r}}$, water contact angles were acquired through the tilting base method (Krüss DSA100) along with the contact angle hysteresis as the difference between the two values $(3 \pm 0.2 \mu \mathrm{L}$ droplet volume). Durability was tested after 30 weeks of ambient condition aging, by immersing the samples in deionized water in an ultrasonic bath (RS Components) and agitating ( $40 \mathrm{kHz}$ for $20 \mathrm{~min}$ at $\left.21^{\circ} \mathrm{C}\right)$. Samples were left for 2 weeks after this step before retesting the sessile water contact angle.

\section{RESULTS AND DISCUSSION}

3.1. Electron Beam-Cu Film Interactions. The interaction between the electron beam and electrodeposited $\mathrm{Cu}$ films was appraised by processing samples with the graduated deposit thickness, generated using EJP parameters in Table 1 . The applied EJP current density $\left(0.022 \mathrm{~A} / \mathrm{mm}^{2}\right)$ was selected as a small percentage $(\approx 12 \%)$ of the theoretical limiting current density calculated from eq 2 . This parameter was selected to create a continuous initial $\mathrm{Cu}$ surface with a high deposition efficiency, evidenced by the relatively smooth as-deposited topographies (see Figure $2 \mathrm{a}-\mathrm{d}$ ) over a range of areal charge densities $\left(0.04-0.40 \mathrm{C} / \mathrm{mm}^{2}\right)$. The sample was subjected to a defined HCPEB treatment ( $30 \mathrm{kV}, 50$ cycles), and the resulting surfaces are shown in Figure $2 \mathrm{e}-\mathrm{h}$. Beading phenomena are observed after HCPEB, where the length scale is influenced by the areal charge density (indicative of deposit thickness). At low deposit thickness (see Figure 2e,f), microbead $(2-20 \mu \mathrm{m})$ features are formed, while at greater thicknesses (see Figure $2 \mathrm{~g}, \mathrm{~h})$, smaller nanobeads $(<1 \mu \mathrm{m})$ are distributed across the surface. The aspherical morphology of the larger beads formed at low deposit thickness is indicative of interdroplet coalescence and wetting in the liquid phase. Complete droplet wetting on the steel substrate is likely to be 
inhibited by the native oxide layer on the steel, which prevents the perfect chemical adhesion between the metallic copper (liquid) and the metallic steel substrate (solid). Analogous to this, complete wetting of the nanobead features, formed on the thick film, is likely to be prevented by native oxide films on the $\mathrm{Cu}$ electrodeposit.

The mean thickness of the as-deposited $\mathrm{Cu}$ film is presented in Figure $2 \mathrm{i}$ over a sampling width of $1.51 \mathrm{~mm}(20 \times$ objective field of view). The area of the mean profile curve $\left(0.717 \mathrm{~mm}^{2}\right)$ is consistent with the theoretical profile area $\left(0.708 \mathrm{~mm}^{2}\right)$ calculated from eq 1 , indicating a deposition efficiency of $\approx 1$. This demonstrates that hydrogen evolution and embrittlement of deposits at these parameters are likely to be limited. The relationship between the length scale of the surface beading and the deposit thickness is likely to be influenced by the efficacy of heat transfer away from the irradiated surface. Considering that the penetration depth of a $30 \mathrm{kV}$ electron beam is generally $<5 \mu \mathrm{m}$ when processing fully dense metals, the deposit thickness will intuitively affect heat transfer, especially where the $\mathrm{Cu}$ film thickness is of a similar magnitude to the heat-affected depth in HCPEB. This is relevant in the context of the differing thermal conductivities of the deposit ( $\mathrm{Cu}$ : up to $400 \mathrm{~W} / \mathrm{mK}$, assuming high density) and the steel substrate $(304$ stainless steel: $<20 \mathrm{~W} / \mathrm{mK})$, which are proportional to the resulting heat flux density.

HCPEB irradiation rapidly melts the surface, where the high surface tension of liquid $\mathrm{Cu}$ dominates over gravitational and viscous forces within the small length scales of the melted zone ( $\approx 10 \mu \mathrm{m}$; see eqs 5 and 6 ). This promotes beading within the applied HCPEB parameters. In the case of thin initial $\mathrm{Cu}$ deposits (see Figure $2 \mathrm{j}$ ), the heat flux across the interface and through the substrate is relatively poor, increasing the liquid lifetime of $\mathrm{Cu}$ allowing beads to coalesce into larger forms. Heat localization then leads to boiling and associated pore formation, with an apparent honeycombed metal foam indicated by the contrast in the micrographs (see Figure $2 \mathrm{e}, \mathrm{f})$ and shown in the section view in Figure 2j. Where the underlying $\mathrm{Cu}$ deposit is thicker, the thermal conduction away from the near-surface is significantly more efficient, and bead solidification is more rapid (see Figure 2k). This phenomenon has also been observed in the HCPEB treatment of hydroxyapatite, which, albeit with poorer thermal conductivity, showed evidence of higher temperatures and more severe heating cycles in regions of lower thickness. ${ }^{24}$ Higher rate solidification prevents coalescence into larger forms. Instead, surface beads fuse together through melting/sintering mechanisms, and smaller submicron beads are visible in Figure $2 \mathrm{~g}, \mathrm{~h}$. This fusion mechanism appears to densify the near-surface layers (see Figure 2k).

Length scales of the nanobeads in Figure $2 \mathrm{~g}$, h are consistent with those observed to influence wettability in films electrodeposited under diffusion control. ${ }^{38}$ This realizes the possibility of achieving similar topographies while depositing higher-quality dense and continuous coatings, using subsequent thermal surface activation.

A mechanism through which the topographic $\mathrm{Cu}$ bead size is influenced by surface cooling rates will leave evidence throughout the resulting microstructures. This is confirmed by the multiple types of microstructure present in the dynamic thickness $\mathrm{Cu}$ sample after HCPEB processing (see Figure 3). A coalesced bead $(\approx 10 \mu \mathrm{m})$ taken from the thin-film region $\left(0.04-0.10 \mathrm{C} / \mathrm{mm}^{2}\right)$ was sectioned with FIB milling (see Figure $3 \mathrm{a})$ to reveal a foam-like structure of disconnected pores. The striking regular spherical morphologies of these pores are unambiguous evidence of formation as gas bubbles within the liquid $\mathrm{Cu}$ phase. While the boiling of $\mathrm{Cu}$ may also be facilitated by the low-pressure (50 pa) environment within the HCPEB chamber, the presence of pores of the same order of length scales as the bead is indicative of poor heat transfer across the interface to the film. Slow cooling rates within this thin-film region are also evidenced by the large-scale grains in the coalesced bead, shown by the bright-field (BF) STEM image and associated single-crystal diffraction pattern (white ring demarcates the approximate pattern acquisition area).

The thick-film region (deposited $>0.10 \mathrm{C} / \mathrm{mm}^{2}$ ) Cu surface is dominated by $<1 \mu \mathrm{m}$ beads (see Figure $3 \mathrm{~b}$ ). In the STEM micrograph of the top surface (adjacent to the protective $\mathrm{Pt}$ ), these beads appear to be individual nanoscale crystallites $(<300 \mathrm{~nm})$, evidenced by the grain contrast in the bright-field (BF) image. Similarly to the thin-film case, the spherical morphology of these surface nanobeads is indicative of their formation from the liquid phase through a beading-type mechanism. The length-scale magnitude of the final beads appears to be proportional to the degree of coalescence, which is in turn dictated by the effective lifetime in the molten phase. Where the heat transfer rate is good (for a thick, dense $\mathrm{Cu}$ film), freezing is rapid and the material grains and surface beads tend toward the nanoscale. Dense $\mathrm{Cu}$ deposits are observed in the STEM micrographs, with no obvious porosity indicating a lack of boiling throughout the thickness of the deposit. Furthermore, no obvious morphological anisotropy is observed. This is also evidence of rapid heat dissipation and cooling rates consistent with HCPEB studies in bulk metals. Nanoscale grain sizes are demonstrated in the SAED pattern of this area, showing the Debye-Scherrer rings more consistent with a powder pattern, in addition to the discrete reciprocal lattice spots. Considering grain boundary strengthening mechanisms, crystallites on this length scale are expected to increase the yield strength of the material from that of the thinfilm "large-grain" region of the sample.

The unmodified $\mathrm{Cu}$ deposit (see Figure 3c) shows a finegrained microstructure consistent with the electrodeposited material, with twinning and some nanoscale porosity (see Supporting Information Figure S2). The STEM micrograph of this material shows that the microstructure of the unmodified as-deposited $\mathrm{Cu}$ is smaller than that of the thin-film region, while being larger than that of the thick-film region. The associated SAED pattern reflects this with evidence of multiple grains but no apparent diffraction rings. Further evidence to support these findings can be found in the FIB-induced SE micrographs of the TEM lamellae, showing ion channeling contrast (ICC) (see Supporting Information Figure S3), revealing contrasting $\mathrm{Cu}$ grain sizes $(0.03-8 \mu \mathrm{m})$.

3.2. Creating Hierarchical Surfaces. For continuous surfaces, the deposit thickness influences the length scale of the electron-beam-induced beading effect and enables control over the small-scale surface topography $(<1 \mu \mathrm{m})$. However, it cannot recreate the multiscale, hierarchical, surface structures that are responsible for naturally occurring hydrophobicity (e.g., the "rose petal" and "lotus" effects). Input energy manipulation in EJP enables control over larger-scale surface topography and the level of discontinuity (see Figure 1c,d), and it is proposed that from this, deposited seed surfaces can be thermally activated to craft hierarchical surfaces.

Introducing larger-scale surface undulations will reduce the effective coating density; therefore, appropriate current 


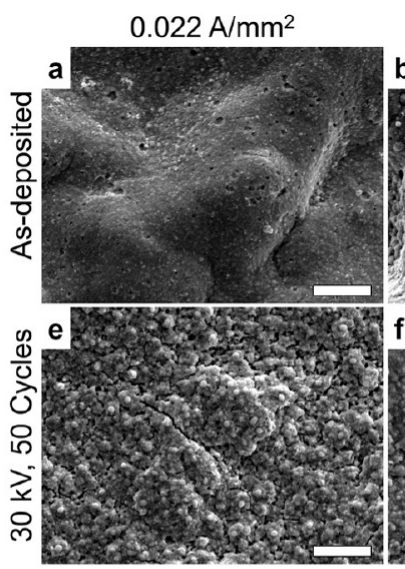

i $S q$ roughness

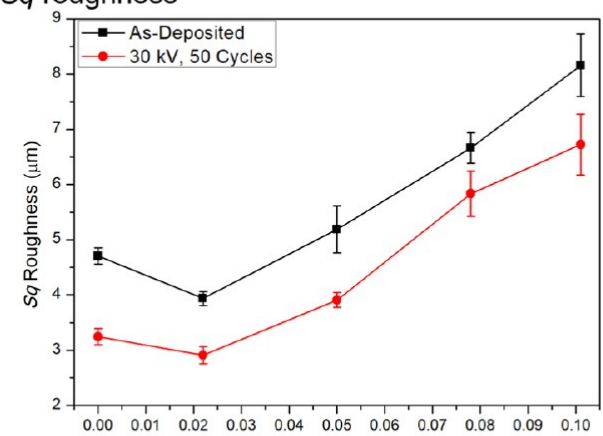

j $\mathrm{S} z$ height Current Density $\left(\mathrm{A} / \mathrm{mm}^{2}\right)$

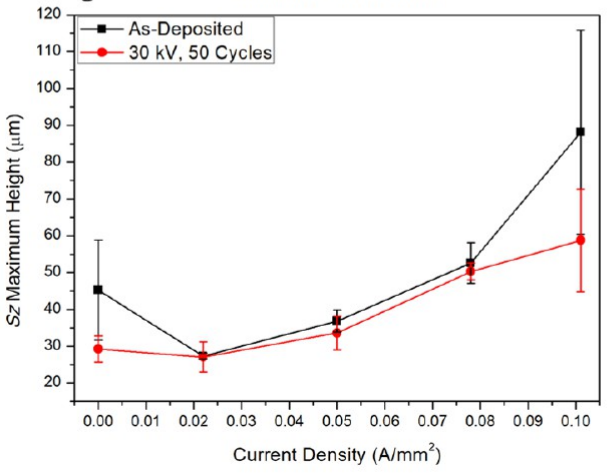

$0.050 \mathrm{~A} / \mathrm{cm}^{2}$

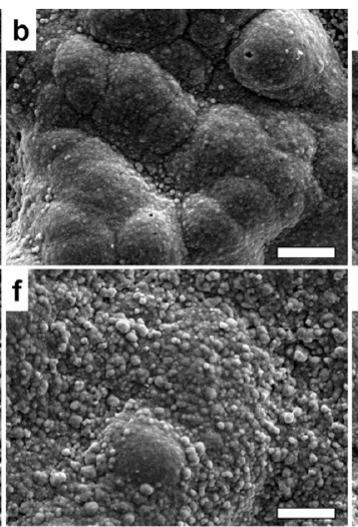

$0.078 \mathrm{~A} / \mathrm{mm}^{2}$
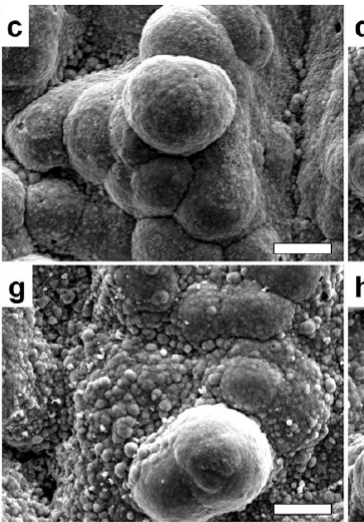

k $0.050 \mathrm{~A} / \mathrm{mm}^{2}, 30 \mathrm{kV}-50$ Cycles

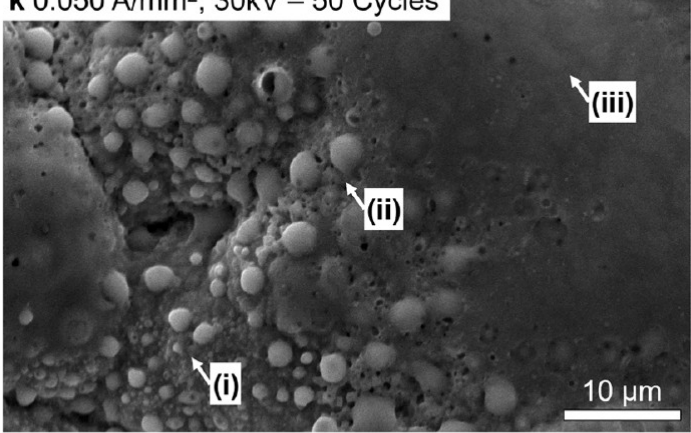

I Mechanism

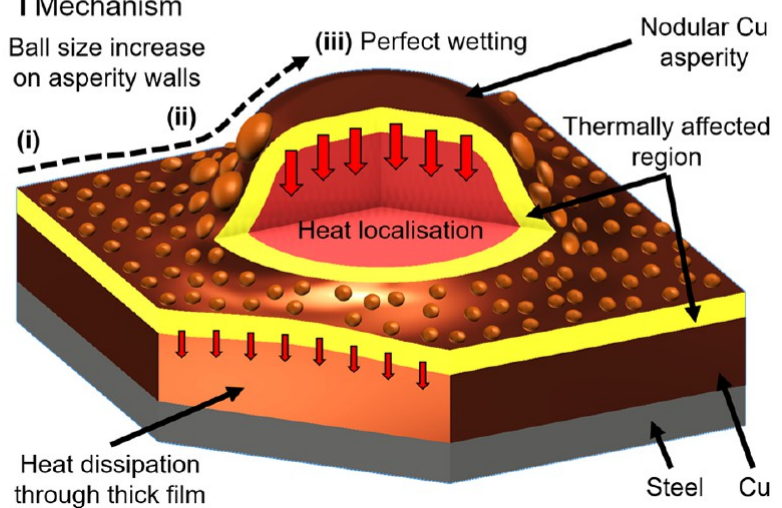

Figure 4. Hierarchical surfaces can be selectively created. Input topography affects microballing phenomena. SE micrographs showing Cu films after electron beam interactions: $(\mathrm{a}-\mathrm{d})$ top row as-deposited, $(\mathrm{e}-\mathrm{h})$ bottom row after HCPEB, with current densities (from left to right): 0.022, $0.050,0.078$, and $0.101 \mathrm{~A} / \mathrm{mm}^{2}$. Increasing discontinuity is observed upon increasing current density. (i) $S_{\mathrm{q}}$ surface roughness reduction upon HCPEB processing. (j) $S_{z}$ roughness showing no major change after HCPEB, except at $0.101 \mathrm{~A} / \mathrm{mm}^{2}$. (k) Length scale of beading increases toward asperity tips, and apparent wetting of $\mathrm{Cu}$ (liquid) improves. (1) This indicates a longer melt lifetime toward the asperity tips, likely caused by poorer heat transfer through the narrow asperity in comparison to the basal film region. Results reported at $0.00 \mathrm{~A} / \mathrm{mm}^{2}$ indicate roughness values of the substrate before and after HCPEB. Error bars are the standard deviation of results from the mean value. Scale bars are $10 \mu \mathrm{m}$ unless indicated.

densities ultimately need to be considered in the context of the end application. Here, the current density was limited to 0.101 $\mathrm{A} / \mathrm{mm}^{2}(\approx 55 \%$ of the limiting current density at the nozzle). "Thick-film" $(>50 \mu \mathrm{m}) \mathrm{Cu}$ was deposited in this study by controlling the areal charge density of electrodeposits (0.35$0.38 \mathrm{C} / \mathrm{mm}^{2}$; see Table 2) to negate the apparent influence of differential heat transfer across the film-substrate interface explored in Section 3.1. A range of input EJP topographies are shown in the SE micrographs in Figure $4 a-d$, where increasing the supply current density $\left(0.022-0.101 \mathrm{~A} / \mathrm{mm}^{2}\right)$ leads to increasing complexity. This is consistent with the conventional electroplating theory, where increasing applied current density increases discontinuity and the number of asperities, as the diffusion-limited condition is approached and the surface concentration of $\mathrm{Cu}^{2+}$ reduces (see Figure $1 \mathrm{~b}$ ). Internodular depressions are shielded from metallic cations, increasing the deposition rate at the sides and peaks of growing asperities. Surfaces acquire morphological characteristics more consistent with fractal self-similarity. ${ }^{39}$ In addition, existing asperities serve to further localize charge transfer (and local current density), resulting in a positive feedback mechanism that accelerates the rate of asperity growth. As such, increasing supply current density beyond $0.101 \mathrm{~A} / \mathrm{mm}^{2}$ could result in local current densities at asperity tips exceeding the limiting current condition and lead to powdery films with poor mechanical properties and hydrogen embrittlement. The effect of initial deposit topography on the beam interaction is shown in the SE micrographs in Figure $4 \mathrm{e}-\mathrm{h}$. Consistent with SE 


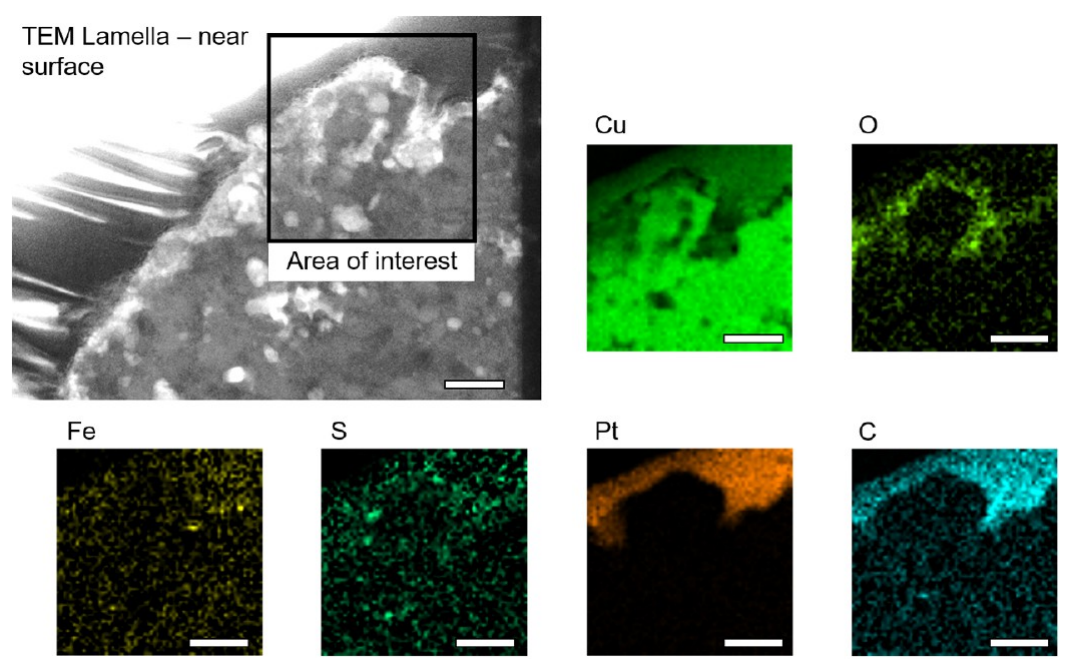

Figure 5. Appraising surface composition with EDS. EDS mapping area marked with a black box. $\mathrm{O}$ and $\mathrm{C}$ signals are shown to be localized in the top $200 \mathrm{~nm}$ of the surface layer, shown in the cross section. Pt signal is a result of the protective coating. TEM scale bars are $500 \mathrm{~nm}$.

micrographs in Figure 2g,h, continuous input topographies (low current density EJP: $\leq 0.050 \mathrm{~A} / \mathrm{mm}^{2}$ ) generate an even distribution of microball features across the deposit surface upon electron irradiation. As such, the surface may be homogenized through the application of HCPEB.

The relationship between surface roughness and applied deposition current density was quantified from FVM datasets. A linear increase in the root-mean-square roughness, $S_{q}$ is shown for the as-deposited $\mathrm{Cu}$ films in the current density range tested (see Figure 4i). At $0.022 \mathrm{~A} / \mathrm{mm}^{2}$, the $S_{\mathrm{q}}$ surface roughness is reduced $(3.94 \mu \mathrm{m})$ from that of the grit-blasted substrate $(4.71 \mu \mathrm{m})$ as a continuous $\mathrm{Cu}$ film is deposited into the grit impact craters. The mean surface roughness increases to $8.16 \mu \mathrm{m}$ at $0.101 \mathrm{~A} / \mathrm{mm}^{2}$ for the as-deposited $\mathrm{Cu}$ film. Consistent with prior HCPEB studies, electron beam irradiation reduces the overall microscale roughness of the surfaces through surface melting and vaporization mechanisms. The maximum height, $S_{z}$, of the as-deposited films also increases in an approximately linear fashion between 0.022 and $0.078 \mathrm{~A} / \mathrm{mm}^{2}$ (see Figure $4 \mathrm{j}$ ). However, $S_{z}$ increases significantly at $0.101 \mathrm{~A} / \mathrm{mm}^{2}$ (mean $88.10 \mu \mathrm{m}$ ). This is the result of an apparent acceleration in the rate of asperity growth and is indicative of the local physicochemical environment at the asperity tips exceeding the limiting current density of the deposition reaction. Discrete fractal dendritic growths protruding relatively long distances $(>100 \mu \mathrm{m})$ from the basal surface film are unlikely to have good mechanical properties; therefore, deposition beyond $0.101 \mathrm{~A} / \mathrm{mm}^{2}$ is not considered relevant in the context of creating robust surfaces, without increasing (i) the bulk $\mathrm{Cu}^{2+}$ concentration or (ii) the impingement velocity. The $S_{z}$ of Cu films created at $0.101 \mathrm{~A} /$ $\mathrm{mm}^{2}$ is shown to decrease upon electron irradiation (mean $58.78 \mu \mathrm{m}$ ), indicating that at least some of these discrete fractal dendritic growths are destroyed by the HCPEB process. This is likely a result of high-magnitude compressive and tensile stress waves $\left(\approx 10^{5} \mathrm{~Pa}\right)$ from the rapid heating and cooling cycles ${ }^{40,41}$ and further evidences the brittle properties of large asperities $(>100 \mu \mathrm{m})$, characteristic of electrodeposition beyond the limiting current density. For $\mathrm{Cu}$ films deposited at lower current densities $\left(\leq 0.078 \mathrm{~A} / \mathrm{mm}^{2}\right)$, HCPEB treatment does not reduce the $S_{\mathrm{z}}$ beyond the range of error, indicating that the largest asperities formed at these parameters largely survive the stress waves generated in electron beam irradiation. It is notable that the $S_{\mathrm{z}}$ values of the as-deposited coating created at $0.101 \mathrm{~A} / \mathrm{mm}^{2}$ approach a relatively high fraction $(\approx 0.2)$ of the total IEG. Without adjusting the IEG, a further layer deposition at these parameters is likely to risk short-circuiting.

As the overall input seed surface roughness increases, the distribution of microbeads appears to localize at the basal areas in the interasperity regions (see Figure $4 \mathrm{k}$ ). This is indicative of a greater surface melting at the tips and could be caused by either (i) a greater electron flux at the asperities ${ }^{42}$ (ii) or restricted heat transfer through the relatively narrow nodular features. A schematic of the asperity-beam interaction is shown in Figure 4l, where the basal region of the deposit (i) shows submicron surface features consistent with those observed for irradiated continuous thick-film $\mathrm{Cu}$ (see Figure 2h). At asperity walls (ii), the scale of the ball features increases and the apparent wetting angle of the liquid phase $\mathrm{Cu}$ reduces, indicative of longer melt lifetimes. The smoother surface at the asperity tip (iii) is indicative of perfect wetting between the liquid and solid $\mathrm{Cu}$ phases or vaporization of the near-surface. Both phenomena are consistent with heat localization in the asperities. Perfect wetting could occur between the liquid and solid $\mathrm{Cu}$ phases (see Figure 4l), which would inhibit the formation of larger-scale beads, such as those observed in thin films where liquid $\mathrm{Cu}$ is in contact with the steel substrate (see Figure 2e).

The near-surface composition of the processed films was appraised by the EDS of the TEM lamella in cross section (see Figure 5), which is also supported by EDS compositional data acquired in the normal view of the same surface (see Supporting Information Figure S6). Consistent with the observations of $\mathrm{Cu}$ films, the near-surface composition is dominated by the native oxide layer, as well as carboncontaining species. The chemistry of surface oxides on the electrodeposited $\mathrm{Cu}$ has previously been shown to be a mixture of $\mathrm{Cu}_{2} \mathrm{O}$ and $\mathrm{CuO}$, with metallic $\mathrm{Cu}$ unlikely at the surface under ambient conditions. ${ }^{5}$ In this study, no SAED diffraction patterns correlating with either $\mathrm{Cu}_{2} \mathrm{O}$ or $\mathrm{CuO}$ oxide phases were isolated from the bulk $\mathrm{Cu}$, despite the relatively high oxygen concentration visible at the near-surface in Figure 5. This indicates a lack of oxide crystallinity. XRD analysis also shows no evidence of reflections that can be attributable to 
either oxide phase (see Supporting Information Figure S4). In prior X-ray photoelectron spectroscopy experiments, carbonbased adsorbed species on electrodeposited metal surfaces have been shown to be dominated by hydrocarbon groups: $\mathrm{C}=\mathrm{C}, \mathrm{C}-\mathrm{C} / \mathrm{C}-\mathrm{H}$ and $\mathrm{C}=\mathrm{O},{ }^{15,38}$ which are proposed to lower the surface energy of the metallic films.

Therefore, the observed surface chemistry appears to be consistent with the time-dependent state of electrodeposited $\mathrm{Cu}$, whereby the oxide and adventitious carbon species effectively lower the surface energy of the coating top surface and lead to interesting wetting properties. Precise quantification of the surface energy is challenged by the relatively complex topography, even of the smoothest surfaces prior to HCPEB treatment (see Figure 4). In addition, the mechanism of time-dependent wetting is related to the adsorption of lowsurface-energy species to the $\mathrm{Cu}$, the efficacy of which is likely to be related to the surface area and therefore the roughness.

3.3. Wetting Properties and Pattern Stability and Durability. The ability to manipulate fluid-facing properties was appraised with the sessile apparent water contact angle (WCA) of deionized water ( $3 \mu \mathrm{L}$ droplet volume, five repeats per sample). WCA was measured as outlined in the Experimental Section after leaving under ambient conditions $>1$ week from the final processing step (see Figure 6).

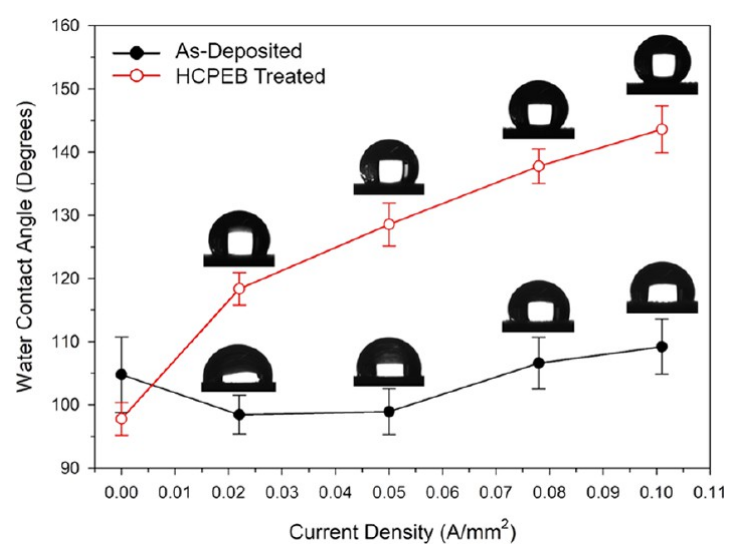

Figure 6. Surface hierarchy dictates functional properties. Sessile water contact angle (WCA) of a $3 \mu \mathrm{L}$ droplet on the as-deposited surfaces and after HCPEB treatments after leaving under ambient conditions for 1 week. Values at $0 \mathrm{~A} / \mathrm{mm}^{2}$ indicate data acquired from the uncoated substrate material. Error bars are the standard deviation from the mean of five data points.

Counterintuitive observation of high apparent hydrophobicity in metals has been determined to result from the adsorption of adventitious species by surface-sensitive techniques like X-ray photoelectron spectroscopy. ${ }^{15,38}$ As-deposited $\mathrm{Cu}$ films have low apparent hydrophobicity $\left(\mathrm{WCA}>98^{\circ}\right.$ ), with no overall increase in hydrophobicity over the grit-blasted steel substrate $\left(104^{\circ}\right)$. A slight increase in WCA is shown for deposition at current densities $\geq 0.078 \mathrm{~A} / \mathrm{mm}^{2}\left(>107^{\circ}\right)$, where the surfaces are more complex. However, the scale of the surface features shown in the SE micrographs in Figure 4c,d is likely too large to fully inhibit wetting and the development of the CassieBaxter-type air-trapping state.

The HCPEB treatment increases the apparent hydrophobicity of the $\mathrm{Cu}$ films deposited at all current densities over the as-deposited coating. While this increase appears counterintuitive considering the decreasing roughness upon HCPEB (see Figure 4i,j), this increase in hydrophobicity is related to the hierarchy of the submicron features (see Figure $4 \mathrm{e}, \mathrm{f}$ ) upon electron beam irradiation, on top of the microscale features measured by FVM. There is a linear relationship between the mean WCA and current density within this current density range $\left(R^{2}=>0.99\right)$. At low current densities $\left(0.022 \mathrm{~A} / \mathrm{mm}^{2}\right)$, the mean WCA is $118^{\circ}$, while at high current densities $\left(0.101 \mathrm{~A} / \mathrm{mm}^{2}\right)$, the mean WCA further increases $\left(144^{\circ}\right)$. This indicates that the HCPEB-generated microscale surface features (see Figure 4e,f) disrupt the wetting properties of the $\mathrm{Cu}$ film. It is likely that an air-trapping wetting state is developed when a water droplet is deposited at the surface of a HCPEB-processed sample. Here, the hierarchical topographies allow trapped air and additional fluid-vapor interfaces, disrupting further wetting. In addition, it should be noted that the hydrophobicity of the uncoated steel substrate decreases slightly upon electron irradiation $\left(98^{\circ}\right)$, likely a result of the smoothing of asperities. This is consistent with the observations of HCPEB treatment of stainless steel ${ }^{43}$ and indicates that the increase in hydrophobicity observed after electron processing of the films is a function of the scale of balling across the surface. It is assistive in the context of creating an industrially viable material processing technique that the highest hydrophobicity is observed at higher current densities, where the mass transfer rates are higher and deposition times are faster.

These samples were retested after an extended period under ambient conditions (30 weeks; see the Experimental Section) to appraise the stability of wetting properties after natural aging treatment. Dynamic contact angles were measured to characterize adhesion properties of the treated surfaces after this time period, following the methodology outlined in Experimental Section. Here, the tilting base method was applied, with advancing and receding contact angles measured at $10^{\circ}$ increments. This was appraised for the smoothest (deposited at $0.022 \mathrm{~A} / \mathrm{mm}^{2}$ ) and the roughest surfaces (deposited at $0.101 \mathrm{~A} / \mathrm{mm}^{2}$ ), both in the as-deposited condition and after thermal activation, referring to the $S_{\mathrm{q}}$ roughness values reported in Figure 4i.

Figure 7 shows the dynamic contact angles recorded for 3 $\mu \mathrm{L}$ water droplets placed on the surfaces deposited at $0.022 \mathrm{~A} /$ $\mathrm{mm}^{2}$ without (Figure $7 \mathrm{a}, \mathrm{b}$ ) and with thermal activation (Figure $7 \mathrm{c}, \mathrm{d})$. In all cases, the droplet stays pinned to the surface when the stage is rotated through $90^{\circ}$, despite both surfaces exhibiting hydrophobic initial conditions $\left(115^{\circ}\right.$ with and $131^{\circ}$ without thermal activation); thus, for this droplet size, there is no observable roll-off angle. Pinning at $90^{\circ}$ tilt with larger droplet volumes $(5,7.5$, and $10 \mu \mathrm{L})$ is additionally shown in Supporting Information Figure S5. Droplet pinning indicates that although even these smoother low current density metallic surfaces are hydrophobic, there are hydrophilic aspects of the topography or chemistry that prevent droplet roll-off and decrease the receding contact angle. This is reflected in the contact angle hysteresis at $90^{\circ}$ tilt, which increases from $31^{\circ}$ for the as-deposited surface to $41^{\circ}$ upon HCPEB treatment. It can be observed that this difference in hysteresis between the surface conditions is driven predominantly by the difference in the advancing contact angle $\left(\theta_{\mathrm{a}}\right.$ $119^{\circ}$ as-deposited and $\theta_{\mathrm{a}} 137^{\circ}$ after HCPEB treatment), rather than the receding contact angle $\left(\theta_{\mathrm{r}} 88^{\circ}\right.$ as-deposited and $\theta_{\mathrm{r}} 96^{\circ}$ after HCPEB treatment).

Figure $7 \mathrm{c}, \mathrm{d}$ shows the dynamic wetting of the roughest surfaces (deposited at $0.101 \mathrm{~A} / \mathrm{mm}^{2}$ ) appraised with droplets of the same volume $(3 \mu \mathrm{L})$. As previously indicated in Figure 

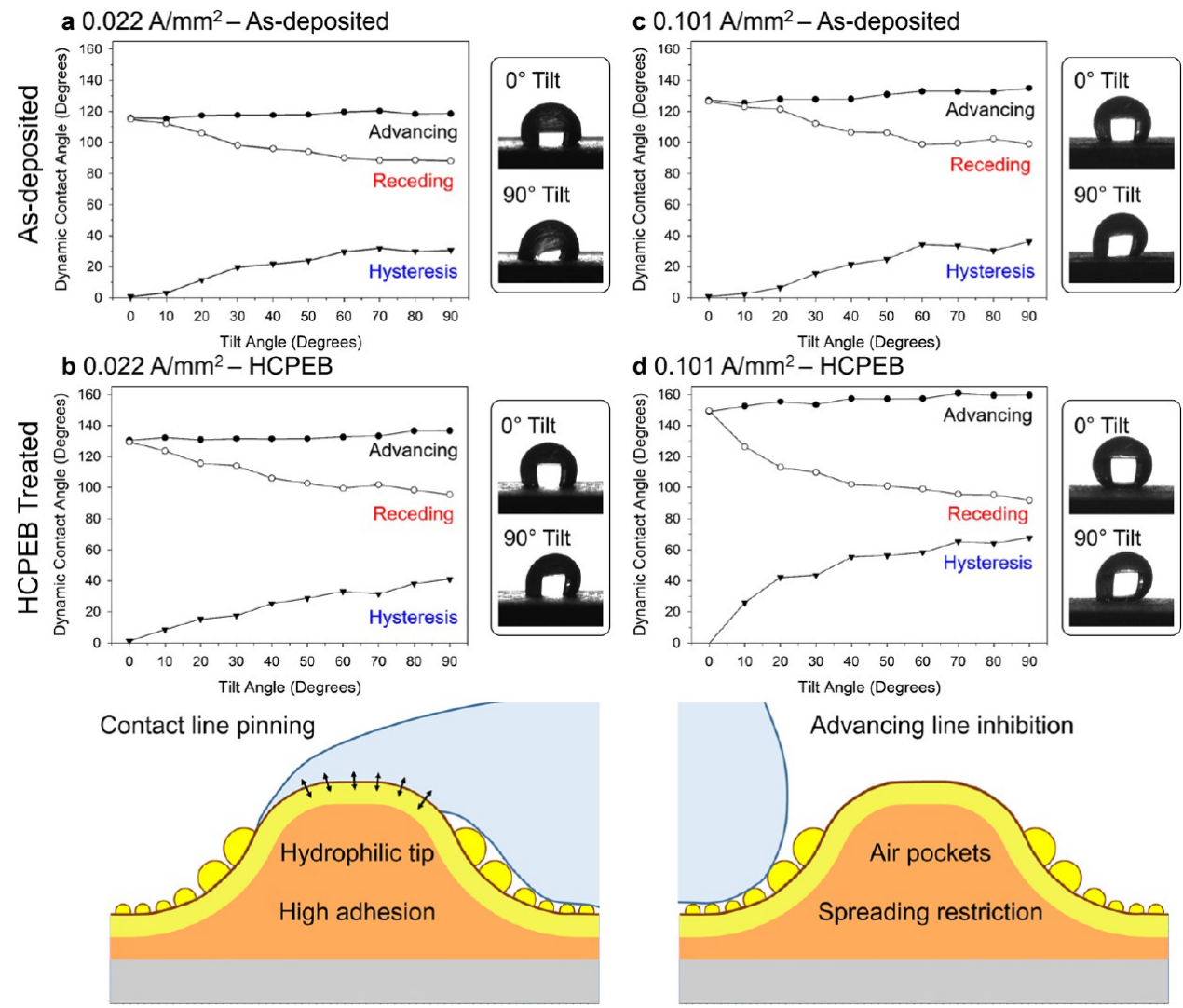

Figure 7. Contact angle hysteresis increases upon HCPEB processing at low current density. Images of droplets at $0^{\circ}$ and $90^{\circ}$ of stage tilt. For (a) $0.022 \mathrm{~A} / \mathrm{mm}^{2}$ as-deposited, (b) $0.022 \mathrm{~A} / \mathrm{mm}^{2}$ after HCPEB treatment, (c) $0.101 \mathrm{~A} / \mathrm{mm}^{2}$ as-deposited, and (d) $0.101 \mathrm{~A} / \mathrm{mm}^{2}$ after HCPEB treatment. Smooth asperities are likely to be responsible for the adhesive effect through contact line pinning, while spreading is likely inhibited by the microbeads. Advancing and receding contact angles are measured with a $3 \mu \mathrm{L}$ droplet.
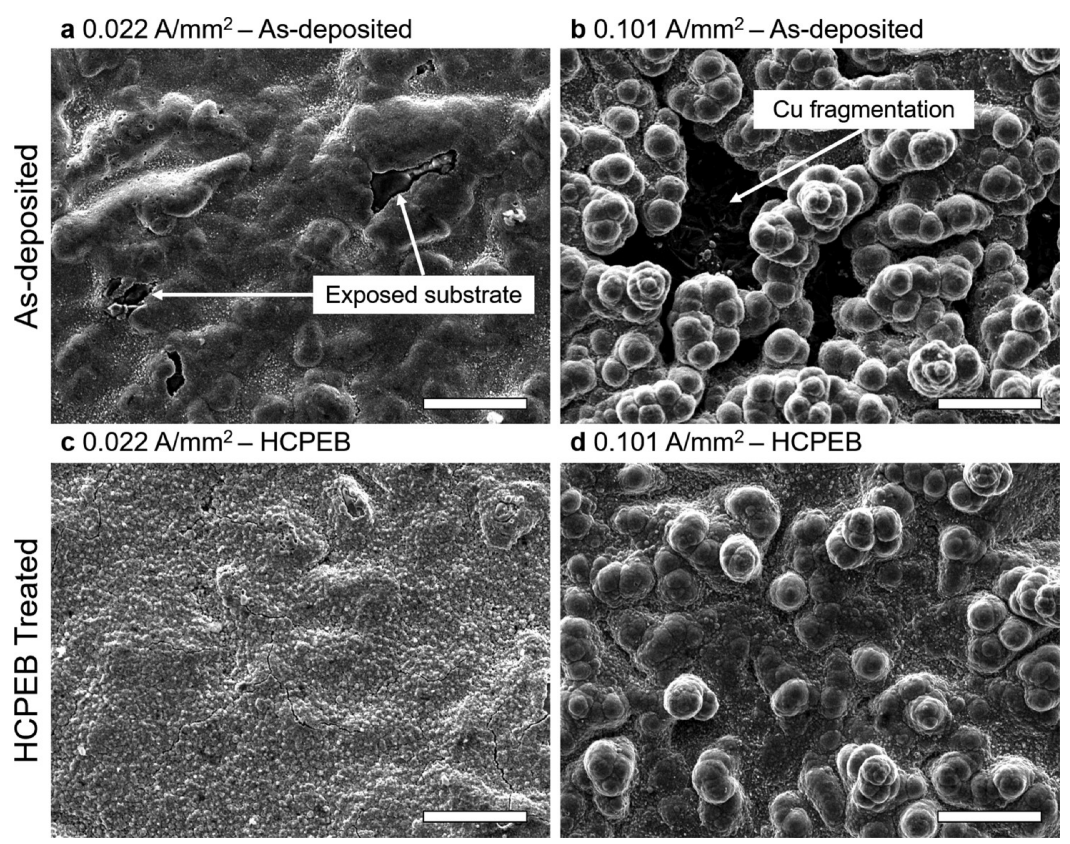

Figure 8. Thermal activation consolidates and strengthens the coating. Observations of samples ultrasonically agitated (20 min at $40 \mathrm{kHz})$ : the asdeposited coating at (a) $0.022 \mathrm{~A} / \mathrm{mm}^{2}$, showing exposed substrate, (b) at $0.101 \mathrm{~A} / \mathrm{mm}^{2}$, showing fragmentation/spalling damage, the HCPEBtreated surfaces at (c) 0.022 and (d) $0.101 \mathrm{~A} / \mathrm{mm}^{2}$ showing no apparent surface damage after the equivalent treatment. SEM scale bars are $50 \mu \mathrm{m}$.

6, the initial sessile contact angles of the two surfaces have high apparent hydrophobicity both in the as-deposited condition and after HCPEB treatment (127 and $149^{\circ}$, respectively).
Despite the surfaces being more hydrophobic than those deposited at $0.022 \mathrm{~A} / \mathrm{mm}^{2}$ (see Figure $7 \mathrm{a}, \mathrm{b}$ ), the droplets are pinned to the surface in the same manner as the stage is tilted 
through $90^{\circ}$, and no roll-off angle is apparent for this droplet volume, or others, up to $10 \mu \mathrm{L}$ (see Supporting Information Figure S5). This is revealed in the similar receding contact angles for the two surfaces at $90^{\circ}$ tilt $\left(\theta_{\mathrm{r}}=99^{\circ}\right.$ as-deposited, $\theta_{\mathrm{r}}$ $=92^{\circ}$ after HCPEB), which are similar to those acquired from the surfaces deposited at low current density. Figure $7 \mathrm{~d}$ shows that the contact angle hysteresis at $90^{\circ}$ tilt is higher for the HCPEB-treated sample $\left(68^{\circ}\right)$ than for the as-deposited surface $\left(36^{\circ}\right)$, where this difference is caused by the difference in the advancing contact angle $\left(\theta_{\mathrm{a}}=135^{\circ}\right.$ as-deposited, $\theta_{\mathrm{a}}=160^{\circ}$ HCPEB).

This state of high hydrophobicity and high adhesion has been observed on natural surfaces, such as the petals of certain roses. ${ }^{44}$ In this case, it is proposed that the microbeading of the topography impedes water droplet spreading, thus increasing the advancing contact angle, most likely through an airtrapping mechanism. This is relevant in the context that both surfaces have been exposed to the same conditions since the last processing step and thus are likely to have similar chemical local surface heterogeneities. Supporting Information Figure S6 indicates that the surfaces all have similar chemical compositions.

The durability of the hydrophobic patterns was appraised by immersing the samples (after 30 weeks of ambient condition aging) in deionized water in an ultrasonic bath $(40 \mathrm{kHz})$, where they were agitated for $20 \mathrm{~min}$ at $21{ }^{\circ} \mathrm{C}$ (see Experimental Section). The effect of thermal activation on the integrity of the hydrophobic patterns after agitation can be observed in Figure 8. The as-deposited EJP films appear to be susceptible to fragmentation and spalling damage resulting from ultrasonic agitation than the thermally activated surfaces, leading to substrate exposure at both high and low current densities (see Figure 8a,b).

This is more prominent for the high current density deposits $\left(0.101 \mathrm{~A} / \mathrm{mm}^{2}\right)$, which appear especially vulnerable to fragmentation. At higher EJP current densities, the deposition rate is greater and the locality of accretion becomes increasingly dependent on diffusion. This means that an interfacial bonding between the film and the substrate is likely to be more inconsistent than that observed at lower current densities (e.g., $0.022 \mathrm{~A} / \mathrm{mm}^{2}$ ); thus, the $\mathrm{Cu}$ layer delamination is easier. Upon fragmentation, the underlying steel substrate can be seen where the coating has locally detached. On the contrary, upon thermal activation, similar fragmentation damage is not apparent in the micrographs at low and high current densities (see Figure $8 c, d$ ), and the integrity of the surface appears to be retained. This indicates that the HCPEB treatment enhances the durability of the hydrophobic patterns, in addition to adapting the wetting properties.

The fragmentation/spalling damage observed in the asdeposited samples is likely caused by ultrasonic-induced microcracking, which would initiate at the interface between the substrate and the coating. On the as-deposited material, these cracks are able to propagate through the coating to the surface where relatively large fragments of deposit are able to separate and be removed by ultrasonic agitation. The HCPEB treatment refines the near-surface $(<6 \mu \mathrm{m})$ metallurgy (see Figure $3 \mathrm{~b}$ ), so it is likely that similar microcracks are formed at the $\mathrm{Cu}$-steel interface in thermally activated samples. However, the refined microstructural properties associated with near-surface grain refinement are likely to attenuate crack propagation, and fragmentation-type damage appears to be limited at the surface.
The long-term stability and the durability of the patterns were appraised by the static droplet method ( $3 \mu \mathrm{L}$ volume) to appraise the effect of (i) natural aging (30 weeks) and (ii) the ultrasonic agitation treatment on the wetting properties of the materials. The surfaces were left for 2 weeks under ambient conditions after ultrasonic agitation to achieve stable surface chemistry. ${ }^{15}$ Figure 9a shows the static water contact angle

a Water contact angle (30 weeks)

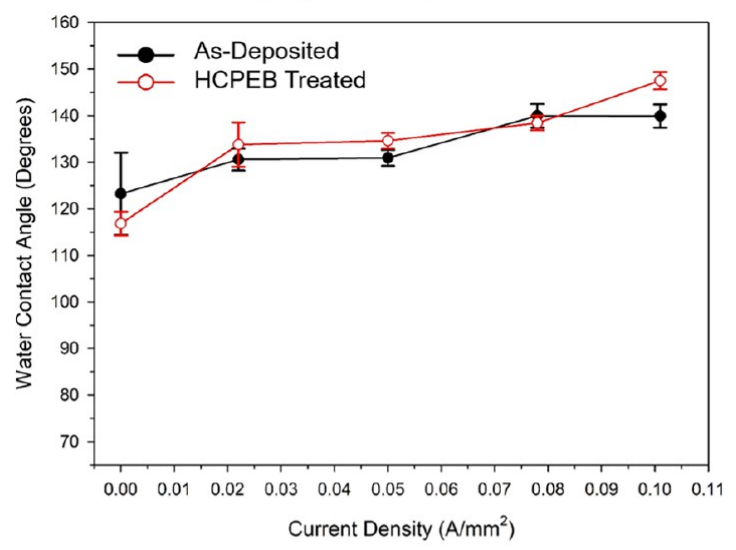

b Water contact angle (Ultrasonic agitation)

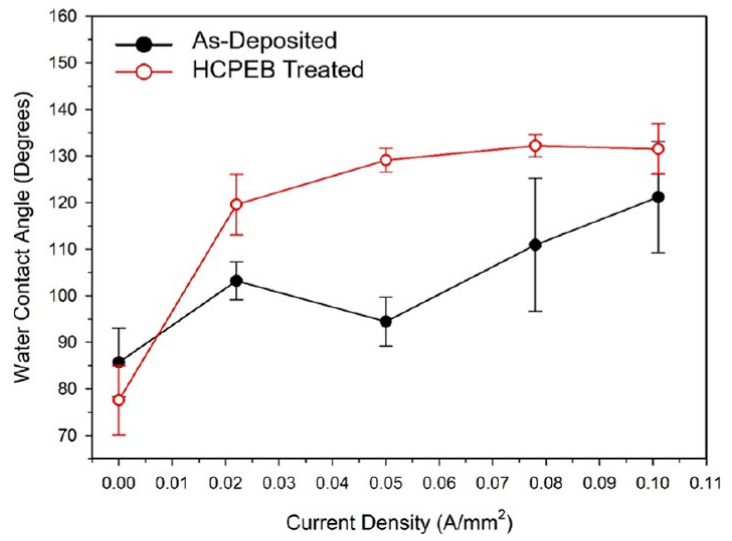

Figure 9. Wettability is stable after 30 weeks, and HCPEB treatment enhances durability. (a) Static water contact angles acquired after a period of 30 weeks from the final processing step. (b) Static water contact angles acquired on the same samples after ultrasonic agitation $(20 \mathrm{~min}$ at $40 \mathrm{kHz})$ and 2 weeks of ambient condition aging. Water contact angles acquired with $3 \mu \mathrm{L}$ droplet volumes. Error bars are the standard deviation from the mean of five repeats.

after 30 weeks of ambient aging (but before ultrasonic agitation), indicating that the wetting properties of the $\mathrm{Cu}$ coatings produced by the combined approach appear not to have degraded over this time period. For the high current density surfaces, the water contact angle appears stable $(0.078$ $\mathrm{A} / \mathrm{mm}^{2}: 138^{\circ}, 0.101 \mathrm{~A} / \mathrm{mm}^{2}: 147^{\circ}$ ), while the lower current density surfaces show an appreciable increase in the apparent hydrophobicity $\left(0.022 \mathrm{~A} / \mathrm{mm}^{2}: 117^{\circ}, 0.050 \mathrm{~A} / \mathrm{mm}^{2}: 135^{\circ}\right)$ when compared with the data acquired after $>1$ week of ambient condition storage (see Figure 6).

In addition, the apparent hydrophobicity of the as-deposited coatings has also increased from the initially recorded values. As the surface topography has not changed over the 30 week time period (see Supporting Information Figure S6), these increases can be explained by gradual changes in surface chemistry, such as further surface oxidation and adsorption of 


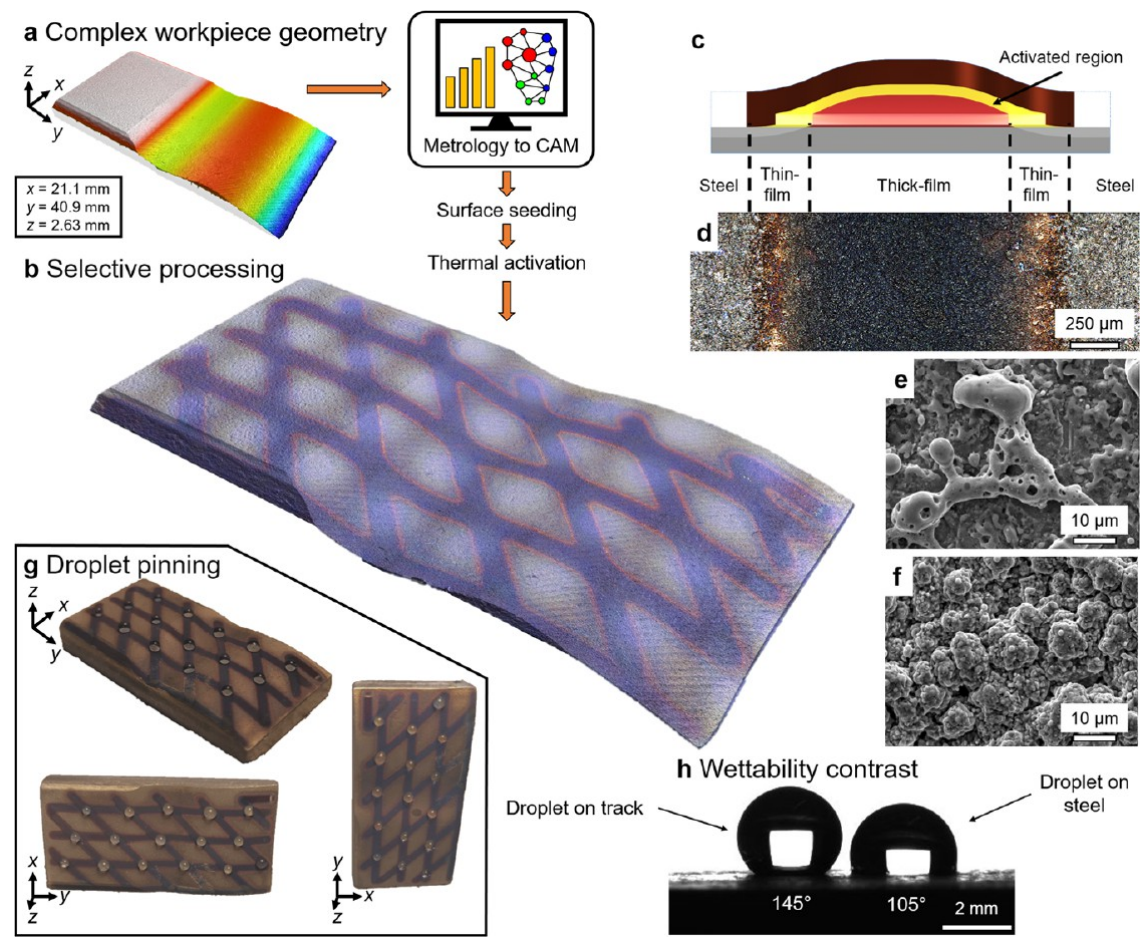

Figure 10. Direct writing of hydrophobic patterns on complex surfaces ( $<10 \mathrm{~min}$ EJP, $<10$ min HCPEB). (a) From a workpiece with complex geometry, metrological inspection reveals surface coordinates onto which EJP coatings can be written (FVM 2.5× objective). (b) EJP and HCPEB processing allows uniform processing over the geometry (FVM 2.5× objective, with overlaid micrograph). (c) Gaussian current density distribution leads to thin-film regions at track edges. (d) These appear more reflective than track centers. (e) Thin-film smooth bead from track edge. (f) Thickfilm rough topography from track center. (g) Workpiece photographs showing water droplets pinned in various sample orientations. (h) Wettability contrast between droplets $(3 \mu \mathrm{L})$ placed on the track (left) and on the diamond-shaped steel substrate (right).

hydrocarbon species over the extended time period. This is also evidenced by the increase in the apparent contact angle of the steel substrate, exposed to the same conditions evidenced in Figure 9a $\left(0 \mathrm{~A} / \mathrm{mm}^{2}\right.$ data $)$ for both treatments, over the same time period (as-deposited: $123^{\circ}$, HCPEB: $117^{\circ}$ ), compared with the initial data acquired after 1 week from the last processing step, shown in Figure 6 (as-deposited: $105^{\circ}$, HCPEB: $\left.98^{\circ}\right)$.

Figure $9 \mathrm{~b}$ shows the water contact angles of the aged surfaces after ultrasonic agitation. Regarding the thermally activated samples, the apparent hydrophobicity is shown to increase from 120 to $132^{\circ}$ across the range: $0.022-0.101 \mathrm{~A} /$ $\mathrm{mm}^{2}$. For the highest current density sample $\left(0.101 \mathrm{~A} / \mathrm{mm}^{2}\right)$, this is a decrease in the mean water contact angle of $12^{\circ}$ from the initial data acquired after 1 week (see Figure 6) and $16^{\circ}$ from the data acquired after 30 weeks of aging, before ultrasonic agitation. For the lowest current density sample $\left(0.022 \mathrm{~A} / \mathrm{mm}^{2}\right)$, the mean water contact angle is within the range of error range $\left(1^{\circ}\right.$ difference) of the data acquired after 1 week and $14^{\circ}$ less than the mean after 30 weeks of aging. Upon ultrasonic treatment, the as-deposited surfaces show lower water contact angles $\left(103-121^{\circ}\right)$ than the thermally activated surfaces across the same current density range (0.022-0.101 $\mathrm{A} / \mathrm{mm}^{2}$ ), with a wider data spread. While the ultrasonic treatment has reduced the apparent hydrophobicity of all surfaces from that shown in Figure 9a, the difference is more marked in the as-deposited samples $\left(27^{\circ}\right.$ at $0.022 \mathrm{~A} / \mathrm{mm}^{2}$ and $19^{\circ}$ at $0.101 \mathrm{~A} / \mathrm{mm}^{2}$ ).

Ultimately, Figure $9 \mathrm{~b}$ shows that the HCPEB-irradiated $\mathrm{Cu}$ films have more stable wetting properties after ultrasonic agitation than the as-deposited films, after identical ultrasonic treatment. This indicates that the thermal activation step and the associated microstructural consolidation have enhanced the durability of the $\mathrm{Cu}$ films. The mechanism through which the HCPEB treatment stabilizes the recorded hydrophobicity is likely through the prevention of surface damage, such as that shown in Figure 8. In particular, it is noticeable that the asdeposited surfaces (after agitation) have a much wider spread of data than the thermally activated samples, which is indicative of inhomogeneous wetting across the $10 \times 10 \mathrm{~mm}$ surface area in the former case. It is considered that the revelation of the less hydrophobic steel substrate upon ultrasonic agitation leads to the differential apparent hydrophobicity across the same sample surface.

3.4. Patterning Hydrophobicity on Complex Surfaces. The combined approach was applied to selectively impose a hierarchical patterned surface on a large $(40 \times 20 \times 2.5 \mathrm{~mm})$ workpiece of complex geometry (see Figure 10a) to demonstrate process versatility and methodological insensitivity toward curved surfaces like aerofoils. From the metrological inspection of a component surface and integration of computer-aided manufacturing technologies, CNC-EJP enables the electrochemical direct writing of free-form $\mathrm{Cu}$ seed surfaces. In this instance, a lattice toolpath $\left(45^{\circ}\right.$ angular separation) was overlaid onto the workpiece, where the IEG was maintained as a function of the nozzle location in comparison to the measured workpiece surface coordinates $(x, y, z)$. The result is shown in the reconstruction in Figure $10 \mathrm{~b}$, after the combined approach to surface creation (EJP: $0.101 \mathrm{~A} / \mathrm{mm}^{2}, 4$ passes, HCPEB: $30 \mathrm{kV}, 50$ cycles). The hydrophobic patterns were written using a $1 \mathrm{~mm}$ I.D. nozzle to maintain experimental consistency with the rest of the study. 

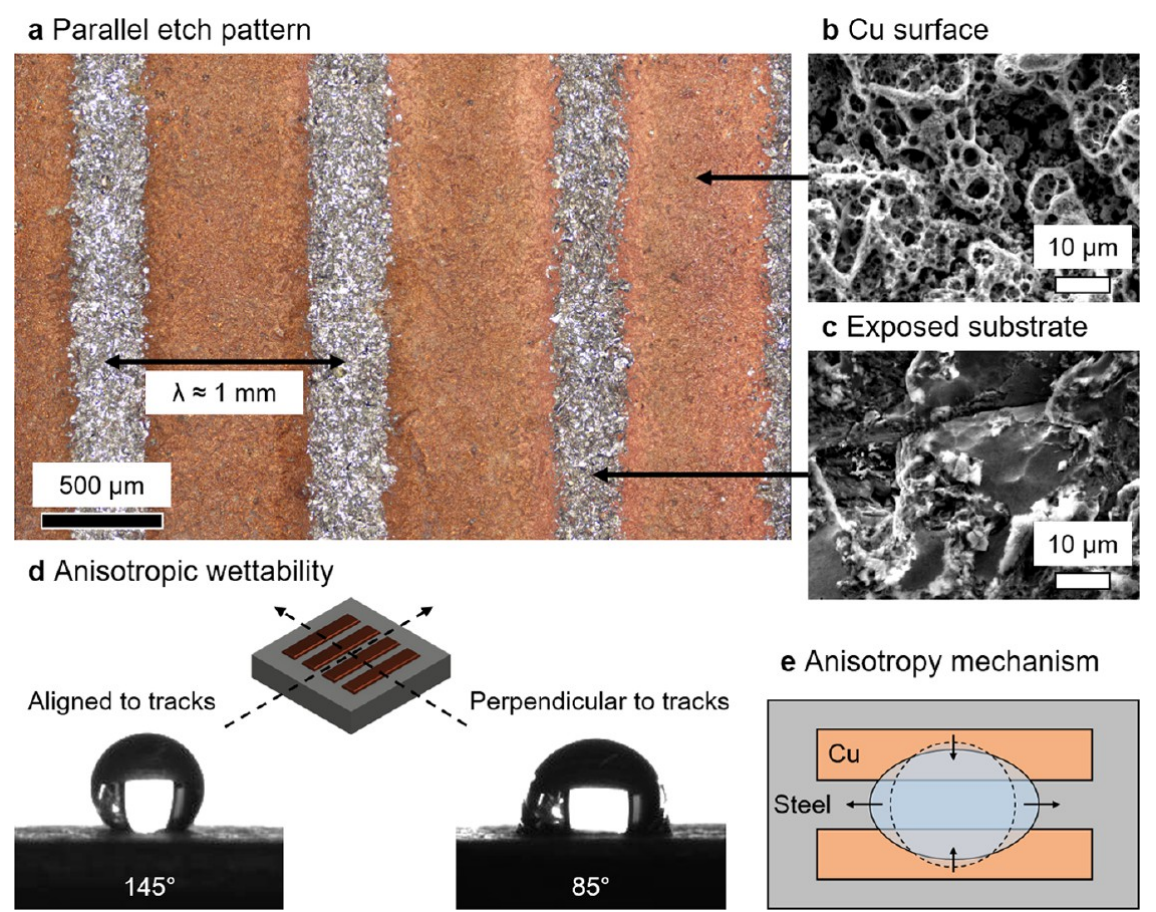

Figure 11. Locally manipulating surface hydrophobicity leads to contact angle anisotropy. (a) Parallel striations electrochemically etched (2.00 A/ $\mathrm{mm}^{2}$; see Experimental Section) into a surface deposited at $0.050 \mathrm{~A} / \mathrm{mm}^{2}$ (striation separation of $1.00 \mathrm{~mm}$ ). Micrographs of (b) Cu film and (c) exposed substrate after the etching process. (d) Surface manipulation leads to anisotropic wettability. (e) This is caused by the differing wettability of the substrate and the $\mathrm{Cu}$.

Higher pattern resolutions in EJP can be achieved by scaling down the nozzle size, where the effective line width is directly proportional to the diameter of the impinging jet and is also influenced by the tilting angle and the electrolyte chemistry. ${ }^{45}$

Consistent with the film thickness findings (see Section 3.1), each discrete track is bounded by a more reflective strip upon irradiation, where the normal current density distribution leads to smaller local deposition masses (see Figure 10c). This is shown in the optical micrograph in Figure 10d, revealing the interface between the substrate, the thin-film, and the thickfilm regions, where the dull appearance in the latter case is indicative of increasing light scattering from the surface of the hierarchically structured material. The larger length-scale beading within the thin-film region leads to increased reflectance.

SE micrographs (see Figure 10e,f) demonstrate the differential length scales in the micro- and nanoscale structuring between the edge and the center of the track, respectively. The latter of which (see Figure 10f) is responsible for the high apparent hydrophobicity of these selective coatings. The photographs in Figure $10 \mathrm{~g}$ show water droplets manually placed onto the track intersections, after which the sample was manipulated into different orientations. A thin film of trapped air can be observed at the interface between the water droplets and the coating, observed as a difference in the refractive index between the two transparent phases. These droplets demonstrate high adhesion to the coating, regardless of workpiece orientation, which is indicative of a complex wetting state, such as "rose petal hydrophobicity" or the Cassie-impregnating state. ${ }^{44,46}$ In this mechanism, the smoother asperity tips (see Figure $4 \mathrm{k}$ ) enable stronger wetting than the nanobead topographies that are likely to trap air pockets more efficiently. ${ }^{47}$ Where the substrate is exposed, a lower water contact angle is observed showing spatial wettability contrast on the complex geometry surface (see Figure 10h).

In addition to direct patterning of $\mathrm{Cu}$, thermally activated electrodeposits can be electrochemically etched using the same EJP setup, simply by switching the workpiece-nozzle polarity to effect anodic dissolution. ${ }^{30,45}$ Through reducing the nozzle diameter for the etching process $(0.25 \mathrm{~mm})$ and by increasing the striation separation distance $(1.0 \mathrm{~mm})$, the $\mathrm{Cu}$ film was dissolved in a controlled manner at an elevated current density $\left(2.00 \mathrm{~A} / \mathrm{mm}^{2}\right)$ to reveal a series of parallel striations of the exposed substrate, shown in the optical micrograph in Figure 11a (see the Experimental Section). In this case, the programmed interstriation separation is approximately equal to the periodicity of the striations. The remnant areas of the $\mathrm{Cu}$ film have also etched in the anodic dissolution process to reveal a high-surface-area metallic foam (see Figure 11b), while the exposed steel substrate topography appears significantly smoother under microscopic inspection (see Figure 11c).

The effect of spatial manipulation of both composition and topography across the surface was appraised by placing a small water droplet $(1.5 \mu \mathrm{L})$ into the center of a striation to observe the interaction between the liquid, the $\mathrm{Cu}$ film, and the steel substrate. The sample was left under ambient conditions for 1 week after the etching step prior to droplet placement. The frames in Figure 11d show the same droplet at $90^{\circ}$ of angular separation, where the left frame is the view parallel to the striations, and the right frame shows the view perpendicular to the striations. The parallel view water contact angle is much greater $\left(145 \pm 1^{\circ}\right)$ than the perpendicular view contact angle $\left(85 \pm 1^{\circ}\right)$. In this case, the high contact angle anisotropy $(\Delta \theta$ $\approx 60^{\circ}$ ) is a result of the hydrophilic etched substrate in comparison to the hydrophobic $\mathrm{Cu}$ surface. Figure 7 shows that the HCPEB-treated $\mathrm{Cu}$ films have high advancing contact angles, which prevents the wetting of the $\mathrm{Cu}$ area fractions. On 
the other hand, the more hydrophilic substrate material leads to droplet distortion and contact angle anisotropy (see Figure $11 \mathrm{e})$.

The additional etching step demonstrates a route through which passive directional fluid transport could be modulated at fine length scales on the metallic surfaces. The high adhesion of the $\mathrm{Cu}$ patterns presented in this study leads to water pinning and thus will decrease the efficacy of the fluid transport routine in comparison to that observed in lower-surface-energy materials, ${ }^{48}$ or $\mathrm{TiO}_{2}$ nanotube arrays, ${ }^{49}$ and arrays modified with organic inks, ${ }^{50}$ which have been shown to be highly efficient at continuous flow transport. However, the thermally activated patterns presented here are shown to (i) be resistant to superficial surface damage, and (ii) the results presented in this study indicate that time-dependent contamination does not negatively affect the apparent hydrophobicity. Both of these factors are assistive for application in adverse external environments. In addition, it is possible that the subsequent modification of these metallic films with low-surface-energy materials will allow for more controlled adhesive properties.

\section{CONCLUSIONS}

A new surface creation methodology has been demonstrated, in which electrochemically deposited surfaces have been thermally activated to create a controlled beading effect. Electrochemical jet processing was applied to selectively electrodeposit predominantly dense $\mathrm{Cu}$ films with good interfacial bonding to the stainless steel in a "direct-write" fashion, and these coatings have been modified using a HCPEB system. The electron beam treatment affects the nanoscale and microscale surface textures, the scale of which can be tuned by the film thickness, which influences the rate of heat transfer from the surface upon HCPEB. In addition, the electron beam treatment has been shown to refine the grain size of the near-surface, which is likely to enhance the mechanical properties such as hardness, through grain boundary strengthening mechanisms. Manipulating the current density can enable the creation of hierarchical surfaces, displaying roughness at multiple length scales, which has been shown to significantly increase the apparent mean hydrophobicity from 98 to $144^{\circ}$ after the HCPEB treatment for samples deposited at $0.101 \mathrm{~A} / \mathrm{mm}^{2}$, which appear stable after 30 weeks and more resistant to ultrasonic agitation than the as-deposited surfaces. The high contact angle surfaces created in this study appear to have high droplet adhesion analogous to "petal effect" hydrophobicity and display high contact angle hysteresis. The combination of techniques has been shown to be applicable to complex, nonplanar surface geometries and has been applied to create periodic patterns displaying anisotropic wetting properties. In addition, faster deposition rates can theoretically be utilized where faster jet impingement velocities and higher concentration bulk electrolyte solutions are deployed.

\section{ASSOCIATED CONTENT}

\section{s) Supporting Information}

The Supporting Information is available free of charge at https://pubs.acs.org/doi/10.1021/acsami.9b20121.

Methodology for sizing surface beads (Figure S1); bright-field and dark-field STEM images of the asdeposited $\mathrm{Cu}$ film (Figure S2); ion-induced SE micrographs of TEM sample lamellae (Figure S3); XRD patterns of $\mathrm{Cu}$ films (Figure S4); pinned water droplets of different volumes (Figure S5); EDS area spectral data (Figure S6); and nonexhaustive table of metals (Table S1) (PDF)

\section{AUTHOR INFORMATION}

\section{Corresponding Author}

Adam T. Clare - Advanced Component Engineering Laboratory, Faculty of Engineering, University of Nottingham, Nottingham NG8 1BB, U.K.; Department of Mechanical, Materials and Manufacturing Engineering, Faculty of Science and Engineering, University of Nottingham China, Ningbo 315100, China; ○ orcid.org/0000-0001-7359-3693; Email: adam.clare@ nottingham.ac.uk

\section{Authors}

Alistair Speidel - Advanced Component Engineering Laboratory, Faculty of Engineering, University of Nottingham, Nottingham NG8 1BB, U.K.

James W. Murray - Advanced Component Engineering Laboratory, Faculty of Engineering, University of Nottingham, Nottingham NG8 1BB, U.K.

Ivan Bisterov - Advanced Component Engineering Laboratory, Faculty of Engineering, University of Nottingham, Nottingham NG8 1BB, U.K.; Texture Jet Ltd., Nottingham NG7 2TU, U.K.

Jonathon Mitchell-Smith - Texture Jet Ltd., Nottingham NG7 2TU, U.K.

Christopher Parmenter - Nanoscale and Microscale Research Centre, University of Nottingham, Nottingham NG7 2RD, U.K.

Complete contact information is available at:

https://pubs.acs.org/10.1021/acsami.9b20121

\section{Notes}

The authors declare no competing financial interest.

\section{ACKNOWLEDGMENTS}

This study was supported by the Engineering and Physical Sciences Research Council [grant numbers: EP/R513283/1, EP/L016206/1, and EP/R025282/1] through the DTP 201819 University of Nottingham, the EPSRC Centre for Doctoral Training in Innovative Metals Processing, and Nanoprime. In addition, the authors would like to thank A. J. Crisp (Advanced Component Engineering Laboratory) for technical support and sample preparation, Nigel Neate (Nanoscale and Microscale Research Centre) for help with TEM sample analysis, and both the Manufacturing Metrology Team and the Centre for Additive Manufacturing (both University of Nottingham) for the use of equipment.

\section{REFERENCES}

(1) Draper, M. C.; Crick, C. R.; Orlickaite, V.; Turek, V. A.; Parkin, I. P.; Edel, J. B. Superhydrophobic Surfaces as an On-Chip Microfluidic Toolkit for Total Droplet Control. Anal. Chem. 2013, $85,5405-5410$.

(2) Gould, P. Smart, Clean Surfaces. Mater. Today 2003, 6, 44-48.

(3) Ma, J.; Zhang, X. Y.; Wang, D. P.; Zhao, D. Q.; Ding, D. W.; Liu, K.; Wang, W. H. Superhydrophobic Metallic Glass Surface with Superior Mechanical Stability and Corrosion Resistance. Appl. Phys. Lett. 2014, 104, No. 173701.

(4) Liu, H.; Szunerits, S.; Xu, W.; Boukherroub, R. Preparation of Superhydrophobic Coatings on Zinc as Effective Corrosion Barriers. ACS Appl. Mater. Interfaces 2009, 1, 1150-1153. 
(5) Wakerley, D.; Lamaison, S.; Ozanam, F.; Menguy, N.; Mercier, D.; Marcus, P.; Fontecave, M.; Mougel, V. Bio-Inspired Hydrophobicity Promotes $\mathrm{CO} 2$ Reduction on a Cu Surface. Nat. Mater. 2019, 18, 1222-1227.

(6) Li, X. M.; Reinhoudt, D.; Crego-Calama, M. What Do We Need for a Superhydrophobic Surface? A Review on the Recent Progress in the Preparation of Superhydrophobic Surfaces. Chem. Soc. Rev. 2007, 36, 1350-1368.

(7) Ma, M.; Hill, R. M. Superhydrophobic Surfaces. Curr. Opin. Colloid Interface Sci. 2006, 11, 193-202.

(8) Shirtcliffe, N. J.; McHale, G.; Newton, M. I.; Chabrol, G.; Perry, C. C. Dual-Scale Roughness Produces Unusually Water-Repellent Surfaces. Adv. Mater. 2004, 16, 1929-1932.

(9) Drelich, J.; Chibowski, E.; Meng, D. D.; Terpilowski, K. Hydrophilic and Superhydrophilic Surfaces and Materials. Soft Matter 2011, 7, No. 9804.

(10) Das, S.; Kumar, S.; Samal, S. K.; Mohanty, S.; Nayak, S. K. A Review on Superhydrophobic Polymer Nanocoatings: Recent Development and Applications. Ind. Eng. Chem. Res. 2018, 57, 2727-2745.

(11) Cheneler, D.; Bowen, J. Degradation of Polymer Films. Soft Matter 2013, 9, 344-358.

(12) Larmour, I. A.; Bell, S. E. J.; Saunders, G. C. Remarkably Simple Fabrication of Superhydrophobic Surfaces Using Electroless Galvanic Deposition. Angew. Chem., Int. Ed. 2007, 46, 1710-1712.

(13) Azimi, G.; Dhiman, R.; Kwon, H.-M.; Paxson, A. T.; Varanasi, K. K. Hydrophobicity of Rare-Earth Oxide Ceramics. Nat. Mater. 2013, 12, 315-320.

(14) Tam, J.; Palumbo, G.; Erb, U.; Azimi, G. Robust Hydrophobic Rare Earth Oxide Composite Electrodeposits. Adv. Mater. Interfaces 2017, 4, No. 1700850.

(15) Wang, J.; Liu, J.; Neate, N.; Bai, M.; Xu, F.; Hussain, T.; Scotchford, C.; Hou, X. Investigation on Time-Dependent Wetting Behavior of Ni-Cu-P Ternary Coating. J. Alloys Compd. 2018, 765, 221-228.

(16) Wang, G.; Zhang, T.-Y. Oxygen Adsorption Induced Superhydrophilic-to-Superhydrophobic Transition on Hierarchical Nanostructured $\mathrm{CuO}$ Surface. J. Colloid Interface Sci. 2012, 377, 438-441.

(17) Brady, R. M.; Ball, R. C. Fractal Growth of Copper Electrodeposits. Nature 1984, 309, 225-229.

(18) Winand, R. Electrocrystallization-Theory and Applications. Hydrometallurgy 1992, 29, 567-598.

(19) Zhao, G.; Li, J.; Huang, Y.; Yang, L.; Ye, Y.; Walsh, F. C.; Chen, J.; Wang, S. Robust Ni/WC Superhydrophobic Surfaces by Electrodeposition. RSC Adv. 2017, 7, 44896-44903.

(20) Jinsong, C.; Jian, G.; Mingbo, Q.; Jianming, Y.; Dazhi, H.; Xiaoli, W.; Yunfei, D. Preparation of Copper-Based Superhydrophobic Surfaces by Jet-Electrodeposition. Mater. Trans. 2018, 59, 793-798.

(21) Yang, X.; Liu, X.; Lu, Y.; Zhou, S.; Gao, M.; Song, J.; Xu, W. Controlling the Adhesion of Superhydrophobic Surfaces Using Electrolyte Jet Machining Techniques. Sci. Rep. 2016, 6, No. 23985.

(22) Li, Q.; Walker, J. D. A. Prediction of Electrodeposition Rates from an Impinging Jet. AIChE J. 1996, 42, 391-404.

(23) Zhao, Y.; Kunieda, M. Investigation on Electrolyte Jet Machining of Three-Dimensional Freeform Surfaces. Precis. Eng. 2019, 60, 42-53.

(24) Stuart, B. W.; Murray, J. W.; Grant, D. M. Two Step Porosification of Biomimetic Thin-Film Hydroxyapatite/Alpha-Tri Calcium Phosphate Coatings by Pulsed Electron Beam Irradiation. Sci. Rep. 2018, 8, No. 14530.

(25) Ozur, G. E.; Proskurovsky, D. I. Generation of Low-Energy High-Current Electron Beams in Plasma-Anode Electron Guns. Plasma Phys. Rep. 2018, 44, 18-39.

(26) Kanaya, K.; Okayama, S. Penetration and Energy-Loss Theory of Electrons in Solid Targets. J. Phys. D: Appl. Phys. 1972, 5, No. 308.

(27) Lukiyanov, F. A.; Rau, E. I.; Sennov, R. A. Depth Range of Primary Electrons, Electron Beam Broadening, and Spatial Resolution in Electron-Beam Studies. Bull. Russ. Acad. Sci. Phys. 2009, 73, 441449 .
(28) Rotshtein, V. P.; Proskurovsky, D. I.; Ozur, G. E.; Ivanov, Y. F.; Markov, A. B. Surface Modification and Alloying of Metallic Materials with Low-Energy High-Current Electron Beams. Surf. Coat. Technol. 2004, 180-181, 377-381.

(29) Matsumoto, T.; Fujii, H.; Ueda, T.; Kamai, M.; Nogi, K. Measurement of Surface Tension of Molten Copper Using the FreeFall Oscillating Drop Method. Meas. Sci. Technol. 2005, 16, 432-437.

(30) Speidel, A.; Su, R.; Mitchell-Smith, J.; Dryburgh, P.; Bisterov, I.; Pieris, D.; Li, W.; Patel, R.; Clark, M.; Clare, A. T. Crystallographic Texture Can Be Rapidly Determined by Electrochemical Surface Analytics. Acta Mater. 2018, 159, 89-101.

(31) Mitchell-Smith, J.; Speidel, A.; Gaskell, J.; Clare, A. T. Energy Distribution Modulation by Mechanical Design for Electrochemical Jet Processing Techniques. Int. J. Mach. Tools Manuf. 2017, 122, 3246.

(32) Chin, D.-T.; Hsueh, K.-L. An Analysis Using the ChiltonColburn Analogy for Mass Transfer to a Flat Surface from an Unsubmerged Impinging Jet. Electrochim. Acta 1986, 31, 561-564.

(33) Karakus, C. Metal Distribution in Jet Plating. J. Electrochem. Soc. 1994, 141, 691 .

(34) Li, R.; Liu, J.; Shi, Y.; Wang, L.; Jiang, W. Balling Behavior of Stainless Steel and Nickel Powder during Selective Laser Melting Process. Int. J. Adv. Manuf. Technol. 2012, 59, 1025-1035.

(35) Bauereiß, A.; Scharowsky, T.; Körner, C. Defect Generation and Propagation Mechanism during Additive Manufacturing by Selective Beam Melting. J. Mater. Process. Technol. 2014, 214, $2522-2528$.

(36) Körner, C.; Bauereiß, A.; Attar, E. Fundamental Consolidation Mechanisms during Selective Beam Melting of Powders. Modell. Simul. Mater. Sci. Eng. 2013, 21, No. 085011.

(37) Lagrange, S.; Brongersma, S.; Judelewicz, M.; Saerens, A.; Vervoort, I.; Richard, E.; Palmans, R.; Maex, K. Self-Annealing Characterization of Electroplated Copper Films. Microelectron. Eng. 2000, 50, 449-457.

(38) Shen, L.; Fan, M.; Qiu, M.; Jiang, W.; Wang, Z. Superhydrophobic Nickel Coating Fabricated by Scanning Electrodeposition. Appl. Surf. Sci. 2019, 483, 706-712.

(39) Hang, T.; Hu, A.; Ling, H.; Li, M.; Mao, D. Super-Hydrophobic Nickel Films with Micro-Nano Hierarchical Structure Prepared by Electrodeposition. Appl. Surf. Sci. 2010, 256, 2400-2404.

(40) Proskurovsky, D. I.; Rotshtein, V. P.; Ozur, G. E.; Ivanov, Y. F.; Markov, A. B. Physical Foundations for Surface Treatment of Materials with Low Energy, High Current Electron Beams. Surf. Coat. Technol. 2000, 125, 49-56.

(41) Proskurovsky, D. I.; Rotshtein, V. P.; Ozur, G. E.; Markov, A. B.; Nazarov, D. S.; Shulov, V. A.; Ivanov, Y. F.; Buchheit, R. G. Pulsed Electron-Beam Technology for Surface Modification of Metallic Materials. J. Vac. Sci. Technol., A 1998, 16, 2480-2488.

(42) Shinonaga, T.; Okada, A.; Miyoshi, T. Prediction of Rounding Phenomenon at Corner Tips in Large-Area Electron Beam Irradiation. Int. J. Mach. Tools Manuf. 2016, 110, 18-26.

(43) Rotshtein, V. P.; Ivanov, Y. F.; Proskurovsky, D. I.; Karlik, K. V.; Shulepov, I. A.; Markov, A. B. Microstructure of the Near-Surface Layers of Austenitic Stainless Steels Irradiated with a Low-Energy, High-Current Electron Beam. Surf. Coat. Technol. 2004, 180-181, $382-386$.

(44) Bhushan, B.; Nosonovsky, M. The Rose Petal Effect and the Modes of Superhydrophobicity. Philos. Trans. R. Soc., A 2010, 368, $4713-4728$

(45) Clare, A. T.; Speidel, A.; Bisterov, I.; Jackson-Crisp, A.; Mitchell-Smith, J. Precision Enhanced Electrochemical Jet Processing. CIRP Ann. 2018, 67, 205-208.

(46) Liu, K.; Yao, X.; Jiang, L. Recent Developments in Bio-Inspired Special Wettability. Chem. Soc. Rev. 2010, 39, No. 3240.

(47) Orejon, D.; Askounis, A.; Takata, Y.; Attinger, D. Dropwise Condensation on Multiscale Bioinspired Metallic Surfaces with Nanofeatures. ACS Appl. Mater. Interfaces 2019, 11, 24735-24750.

(48) Xu, C.; Feng, R.; Song, F.; Wu, J.-M.; Luo, Y.-Q.; Wang, X.-L.; Wang, Y.-Z. Continuous and Controlled Directional Water Trans- 
portation on a Hydrophobic/Superhydrophobic Patterned Surface. Chem. Eng. J. 2018, 352, 722-729.

(49) Lai, Y.; Huang, J.; Cui, Z.; Ge, M.; Zhang, K.-Q.; Chen, Z.; Chi, L. Recent Advances in $\mathrm{TiO} 2$-Based Nanostructured Surfaces with Controllable Wettability and Adhesion. Small 2016, 12, 2203-2224.

(50) Lai, Y.; Pan, F.; Xu, C.; Fuchs, H.; Chi, L. In Situ SurfaceModification-Induced Superhydrophobic Patterns with Reversible Wettability and Adhesion. Adv. Mater. 2013, 25, 1682-1686. 